\title{
HUMANISMO Y ATEÍSMO EN LA FILOSOFIA DE NICOLAI HARTMANN
}

\section{Introducción}

Puede decirse que la presencia de lo divino, lo numinoso o lo tremendum, según sabemos o vislumbramos a través de monumentos, pinturas y escritos, es simultánea a la aparición del hombre como hombre, es decir, como poseedor de un mínimo de observación de los fenómenos y de reflexión sobre su sentido o enlace, al menos posible, con algo no fenoménico, si bien esto a veces simbolizado, representado o aun identificado con elementos materiales de la experiencia. El pendant hombre-Dios puede considerarse, por tanto, como originario, y naturalmente también sus relaciones. Las positivas, es decir, de afirmación (aceptación, sumisión, acatamiento, entrega), están acreditadas desde un principio por toda manifestación de tipo religioso. En cuanto a las negativas, es decir, de negación (rechazo, desobediencia, oposición, rebeldía) las conocemos por ciertos mitos y aun por algunos temas bíblicos - sin duda relativamente muy cercanos en la evolución del hombre. Dentro de la mitología griega, por ejemplo, se hallan múltiples testimonios de la rebelión del hombre contra los dioses y contra el destino, y en ella se plasmó un símbolo extraordinario: Prometeo. En la Biblia, de carácter esencialmente religioso, encontramos, a pesar de ello, no sólo el Non serviam de la soberbia y afirmación de la creatura -ángel u hombre-, sino además el Dixit impius in corde suo: non est Deus de la negación expresa, si no teórica al menos práctica, de la existencia de Dios.

La originalidad fáctica de la presencia y aun del enfrentamiento del hombre y de Dios es, sin embargo, sólo un aspecto, o mejor, un indicio de la originariedad interna o por principio. En efecto, los caracteres esenciales atribuidos casi universalmente a Dios y al hombre implican un vínculo estrecho y necesario, cuya concepción se centró básicamente en la dependencia del segundo respecto del primero. El grado máximo de tal dependencia lo señala el concepto de creación, extraño, por ejemplo, al pensamiento griego. Otros grados son la conservación y el concurso, la providencia y la predestinación. Dios es creador y conservador del hombre, Dios concurre necesariamente para llevar a cabo la mínima acción suya, Dios cuida, provee y prevé las necesidades de su futuro inmediato, y destina o determina por anticipado -según nosotros- su futuro remoto, permanente y último. El hombre es la creatura necesitada de sostén y ayuda, de cuidado y orientación, de descanso, perfección y asentamiento definitivos. Dios es el ser infinito, perfecto, necesario, absoluto; el hombre, el ser finito, imperfecto, contingente, relativo. 
Según los conceptos básicos, pues, la correlación entre hombre y Dios aparece como necesaria -desde luego con la precisión, teológica, de que la necesariedad es por parte del hombre, es decir, bajo la suposición de que éste existe. Por tanto, en principio, y sin determinar aún las proporciones de la implicación, debe admitirse que humanismo y ateismo guardan estrecha dependencia, así como la pueden guardar también teismo y antihumanismo. En consecuencia lógica, de esta posición se deduciría inmediatamente que todo humanismo implica un ateismo y que todo teismo encierra un antihumanismo. A primera vista la conclusión parece inadmisible, pues, por una parte, ningún humanista concederfa ser por ello ateo, e históricamente no todo humanismo ha llevado a un ateísmo, ni todo teísmo a un antihu. manismo; por otra, tampoco todo ateísmo condujo a un humanismo, ni todo antihumanismo a un teísmo. Sin embargo, ya en varios momentos de la historia - por ejemplo, la Edad Media en favor del teísmo y el Renacimiento en favor del humanismo- sí se ha vislumbrado tal implicación y planteado el insondable y quizá insoluble problema que encierra. Pero lo decisivo al respecto no es el hecho de que haya ocurrido eso o no, según dijimos anteriormente, sino la implicación objetiva del concepto y de la realidad misma. Pero, el supuesto fundamental es la relación, hipotéticamente necesaria, entre los dos términos, Dios y el hombre, que se señaló antes. Porque, estrictamente hablando, la posición del ateísmo exigiría la inexistencia de uno de los términos relacionados y, por tanto, caería por su base la implicación. En otras palabras, si no existe Dios, no hay problema para el hombre. Mas precisamente el planteamiento es hipotético: de existir Dios, ¿qué consecuencias le resultan al hombre? Si Dios existe, ¿puede ser el hombre lo que es, lo que puede, debe y quiere ser? ¿Significa la existencia de Dios algo positivo o algo negativo para el hombre? Base de la hipoteticidad de ese planteamiento es que la existencia de Dios no es evidente; respecto de la existencia del hombre, en cambio, no puede plantearse lo mismo, pues ésta es un hecho de la experiencia.

Acerca de los grados de implicación entre humanismo y ateísmo -y entre teísmo y antihumanismo- deben distinguirse, en primer lugar, un sentido genérico y uno especifico de los términos. Por el primero entiendo yo todo tipo de afirmación que en cualquier sentido limite, disminuya o restrinja —s decir, signifique una negación parcial - los caracteres esenciales. del concepto respectivo. Así por ejemplo, toda reducción de los atributos. divinos viene a significar un ateísmo parcial o particular, por cuanto niega algo divino. $\mathrm{Y}$ también, toda reducción de los atributos humanos viene a significar un antihumanismo parcial o particular, en cuanto niega algo humano. Por sentido específico entiendo la afirmación o negación radical y total de lo significado por el concepto. Así, la posición o supresión simple y llana de la existencia de Dios o de la esencia del hombre significarán un 
teísmo o un ateísmo, un humanismo o un antihumanismo universales y abso. lutos. De aqui, en segundo lugar, se puede establecer una sencilla ley de proporción: a mayor negación de Dios, mayor afirmación del hombre; e inversamente, a mayor negación del hombre, mayor afirmación de Dios. $\mathrm{Y}$ al grado máximo de la afirmación corresponde el grado máximo de la negación: existencia -inexistencia o aniquilación.

Esto último parece tener visos de sofisma. En efecto, la coexistencia no parece imposible, más aún, sería necesaria, en cuanto que, supuesta la existencia del hombre como creatura finita, contingente y sin la razón de ser en sí misma, se exige absolutamente un creador infinito, necesario y con la razón de ser en sí mismo. Sin embargo, esa coexistencia implica en un ser elementos o caracteres que no anulen los del otro ni sean contradictorios de ellos directa y específicamente. Para que la coexistencia sea posible, es necesario que las afirmaciones y las negaciones se encuentren en un punto medio y logren un equilibrio. Sin duda, los grados máximos imposibilitarían la coexistencia; y después, relativa y proporcionalmente, todo grado que se alejara del término medio.

Tratemos de concretar esto: si por exigencias humanas los caracteres del hombre (por ejemplo, voluntad, inteligencia, poder, libertad, etc.) son elevados más allá de su medida y alcanzan el grado máximo de elevación, ya no serán los caracteres del hombre sino los atributos de Dios, se habrá atribuido al hombre lo que es de Dios, se habrá identificado al hombre con Dios y se habrá negado a Dios como absolutamente diverso del hombre; resultado final: humanismo en una faceta y ateismo en otra. Inversamente, si por exigencias divinas los caracteres del hombre se rebajan más allá de su medida y alcanzan el grado máximo de reducción, entonces no serán tampoco ya los caracteres del hombre sino los de un ser inferior, al cual ya no competen por esencia aquéllos, no se podrá atribuir al hombre lo que le pertenece, se habrá desidentificado al hombre con relación a sí mismo; resultado final: antihumanismo en un aspecto y teismo en el otro.

El aspecto del teísmo podría no parecer claro; para esclarecerlo reformulemos todo lo anterior así: si por exigencias humanas los atributos divinos se rebajan más allá de su medida y alcanzan el grado máximo de reducción (sin desaparecer el carácter o tipo esencial), ya no serán los atributos de Dios sino los caracteres del hombre, se habrá atribuido a Dios lo que es del hombre, se habrá identificado a Dios con el hombre y se habrá negado a Dios..., etc. Aquí el resultado final es ateismo por un lado y humanismo por otro. Igualmente: si por exigencias divinas los atributos de Dios se elevan más allá de su medida (esto se considera de por sí imposible, pues no puede haber un grado más allá del máximo; pero debe entenderse, más allá de la medida implicada por la esencia de Dios y la del hombre) y alcanzan el grado máximo de elevación, entonces los caracteres del hombre desapa- 
recerán, él quedará reducido a un ser inferior, al cual ya no competen..., etc. Aquí, a su vez, el resultado final sería teismo por una parte y antihumanismo por otra.

Como ejemplificación histórica de todo lo anterior podemos considerar los siguientes casos. La ignorancia o el olvido de Dios, probable al menos en ciertos momentos de la historia, hace resaltar al hombre, por cuanto en eI ámbito del ser sólo aparece él — sin duda frente a la demás naturaleza creada-, el hombre existe únicamente para sí y se dedica a sí mismo, y su vida es como si no existiera otro ser fuera de él. Este podría llamarse ateismo natural, ingenuo o inconsciente. El olvido y menosprecio o la negación del hombre han tenido como origen en muchas épocas históricas el énfasis excesivo, rayano a veces en la afirmación absoluta, de lo divino: tal es, por ejemplo, la posición de las más importantes religiones orientales; pero también se encuentra esto en el meollo mismo de la religión cristiana, cuya mística y ascética ( $y$ en cierto grado aun la dogmática) insisten en la negación, supresión y aniquilamiento del propio yo, de la propia voluntad, del propio criterio y entendimiento; en la entrega de la propia persona y de la propia libertad; en el desplazamiento de todo lo humano para que penetre lo divino, y sea, en definitiva, Dios quien exista y no el hombre. Sin duda hay precisiones y limitaciones fundamentales a esto: pero en muchos puntos aun la más profunda y avanzada teología no ha podido hallar salida para las aporías y antinomias que significa el encuentro del teísmo y del humanismo, de Dios y del hombre. El humanismo del Renacimiento es reacción elocuente contra el teísmo medieval; y es conocido de todos el aspecto esencialmente humanístico de todos los ateísmos y materialismos modernos -independientemente de modalidades en la concepción del hombre: modalidades que, filosóficamente, se mantienen en el plano accidental, es decir, no tocan la esencia del hombre, por más que le nieguen a éste toda capacidad y todo enlace trascendentes. Aquí corresponden, entre otros muchos filósofos y pensadores, un Marx, un Sartre, un Hartmann.

\section{Planteamiento}

Ciertas doctrinas y tendencias de la filosofía de Nicolai Hartmann plantean en forma más notoria que las de otros filósofos contemporáneos el complejo problemático esbozado en las disquisiciones anteriores. Precisamente la gran frecuencia con que Hartmann trata el tema invita a estudiar más de cerca y en su conjunto la posición del filósofo. En realidad, parece extraño a primera vista que un filósofo de su procedencia y con sus características de cuidado metódico, limpia objetividad y rectitud de propósitos aborde tan repetida e insistentemente una problemática que no cae de manera directa en el campo de sus especulaciones -excepto quizá en la Ética- y adopte 
una actitud con aspectos de preconcepción y tratamiento menos científico de los problemas.

Si se leen, en efecto, las obras principales de Nicolai Hartmann con el designio de estudiar la posición del filósofo acerca del problema de Dios, se tropieza uno con tres hechos evidentes, de los cuales los dos primeros son importantes en lo formal y externo, y el tercero en lo que se refiere al contenido. El primero concierne a la gran frecuencia, mencionada antes, con que Hartmann habla acerca de este problema; el segundo se refiere a la actitud polémica - con frecuencia irónica, algunas veces sarcástica- contra otras direcciones filosóficas, contra todo pensamiento que reconozca la existencia de Dios y afirme algo positivo acerca de El y pretenda probarlo; el tercero es el enfrentamiento radical, la disyunción casi absolutamente contradictoria entre Dios y el hombre, que el filósofo cree encontrar y pretende demostrar.

Acerca del primer hecho se advierte que en todas sus grandes obras - -exceptuando la Filosofía de la naturaleza y la Estética- aprovecha cualquier oportunidad para entrar en el problema, repitiendo muchas veces los mismos motivos. Con todos los pasajes en que Hartmann habla al respecto se podría formar muy bien un regular tratado sobre la existencia de Dios, su conocibilidad, demostrabilidad, relación con el hombre, etc. Puede decirse que Hartmann escribe sobre el tema mucho más que otros filósofos, quienes por su procedencia y sus ideas deberían haber tratado con amplitud el tema en obras específicas. El libro Pensamiento teleológico se podría llamar también Pensamiento teológico, 1 pues toda la obra investiga la teleología, en forma muchas veces indirecta, casi exclusivamente bajo el aspecto de que desde antiguo se la tomó como fuente para la demostrabilidad de la existencia de Dios. Las palabras Dios, divinidad, divino, etc., ocurren algunas veces con tanta frecuencia - en especial en la Ética-, que inmediatamente se tiene la impresión de que este problema encierra para Hartmann una importancia especial, una significación particular, quizá mayor que para otros filósofos, para quienes es menos "problema". Todo esto lleva a preguntarse, por qué razones se ocupa Hartmann de ese problema en tantos pasajes. ¿Es sólo un interés teórico, es decir, el de la investigación y discusión de un determinado problema en forma puramente objetiva, "cientificamente", sin tomar partido, dirigiéndose sólo hacia la verdad? Entre otras cosas el propósito de este trabajo es contestar a dicha pregunta, pues un hecho externo puede conducir -y conduce realmente - a la toma de posición del filósofo en el problema. El segundo hecho se halla a mi parecer en conexión con el primero y el

1 En forma curiosa el título aparece confundido, precisamente como se indica, en el libro de P. Bochenski Europäische Philosophie der Gegenwart, $2^{\mathrm{a}}$ ed. 1951, p. 219 , nota. Sin duda la confusión se debe a la semejanza de las dos palabras, mas podría haber influido el tema mismo. 
tercero. Una actitud polémica continua y siempre enérgica, en efecto, muestra por decirlo así en crescendo el interés por el tema $y$, también de ordinario, por una toma de posición determinada. Un filosofar en realidad específicamente teórico no necesita de la polémica, pues aquél procede a partir de la cosa, de los fenómenos, y no desde la posición de los otros. La polémica quiere ante todo demostrar algo contra otra tesis o contra otro. La filosofía tiene en primer lugar el propósito de la verdad y sólo secundariamente, como consecuencia, la destructio erroris. Pero esta actitud polémica se corresponde también con el tercer hecho, puesto que Hartmann toma el partido del hombre frente al de Dios, el partido de aquellos que afirman al hombre sobre o sin o aun contra Dios, y no el partido de aquellos que ponen a Dios sobre o fuera del hombre. La polémica es en lo subjetivo lo que la oposición Dios-hombre significa objetivamente.

El tercer hecho constituye en mi opinión el núcleo de la filosofía de Nicolai Hartmann a este respecto. Es, por decirlo así, la intención última, la meta de las ideas y de los argumentos del filósofo. Todo lo que Hartmann expresa acerca de Dios, acerca de su existencia y esencia, acerca de la demostrabilidad de su existencia tanto en general como sobre las diversas pruebas, apunta a salvar al hombre de la aniquilación por obra de Dios. La filosofía de Hartmann, es cierto, no tiene como último o primer fin la negación de Dios propiamente. Esto resulta en él más bien como supuesto de la salvación y de la afirmación del hombre. El pensamiento hartmanniano, por tanto, bajo este aspecto, puede considerarse primariamente como humanistico y, secundariamente, en cuanto consecuencia necesaria - de acuerdo con sus principios-, como ateistico; de manera que no es remota ni impracticable la posibilidad de descargar su pensamiento del ateísmo, en tanto que los presupuestos de su humanismo no contuvieran aquél incondicionadamente. En otras palabras, si las razones y argumentos del filósofo, entendidos en forma correcta, defienden y prueban en verdad el humanismo, pero sin decir necesariamente algo radical contra Dios, entonces el ateísmo, por decirlo así, es concluido de manera incorrecta a partir de fundamentos no vistos quizá con suficiente claridad. Yo tengo esto por posible, pues Hartmann - como quizá no lo ha pretendido ningún filosofo en la historia - no rechaza directamente a Dios, digámoslo así, sólo por rechazarlo, porque tuviera fenómenos y argumentos teóricos inmediatos, independientes de toda otra finalidad, sino porque necesita de ello o cree necesitar para salvar al hombre, para reestablecer de nuevo la dignidad del hombre. Todo esto, sin embargo, resulta dicho muy breve y simplemente. El camino del filósofo es muy complicado y no ofrece mucha claridad en las diversas fases y estadios de su pensamiento. Aquí se tratará de exponer los puntos principales tan sistemáticamente como sea posible y en el contexto apropiado, de acuerdo con el enorme y variado material disponible y las vacilaciones del filósofo. 
La crítica que se ha hecho al pensamiento de Hartmann en este problema caracterizó su posición como "ateísmo postulatorio". 2 Acerca de esa crítica debe notarse lo que sigue: al enfocar el pensamiento de Hartmann en el problema de Dios, se ha tomado hasta ahora en consideración casi exclusivamente el aspecto práctico, ético, según el cual parece inferirse casi sin duda un ateísmo postulatorio. Para ello se suele hacer referencia general sobre todo a los más conocidos e importantes pasajes de la Etica y a los análogos del libro Pensamiento teleológico. En cambio, el aspecto teóricagnoseológico apenas si es mencionado y tenido en cuenta. Constituyen ese aspecto las afirmaciones puramente teóricas de Hartmann sobre la conocibilidad de Dios, la demostrabilidad de su existencia, las diversas pruebas para ello, la fuerza y alcance de la razón humana, etc. Que este campo no haya sido hasta ahora investigado, parece depender del hecho de que en cierto modo Hartmann no lo trata directamente y de que, si se leen los indices de sus obras,

$2 \mathrm{He}$ aquí algunos juicios al respecto: el Lexikon der Theologie und Kirche, Art. Atheismus (redactado por Karl Rahner), II Philosophisch, dice: "...La negación de la existencia o de cualquiera (no solamente racional) conocibilidad de Dios (A. teorético)." Y luego: "Ciertamente son ateístas todos los sistemas del materialismo (...); todas las formas de un A. postulatorio, es decir, teorias, que, como (...) la ética ateísta-postulatoria de Nicolai Hartmann, pretenden demostrar positivamente que Dios no puede ni debe existir." Citado por Paul Hossfeld en el artículo que se menciona al final de esta nota. un crítico, objetivo aunque severo, resume asi su juicio: "En este contexto Nicolai Hartmann defiende una posición teóricamente más limpia, pues sólo exige, pero no demuestra, su ateísmo, y en el fondo tampoco pretende demostrarlo, de manera que se puede hablar en él de un ateísmo postulatorio. Esta exigencia suya es naturalmente un gran error, como habrá de señalarse luego en forma brave." Y más adelante: "Én actitud parecida Nicolai Hartmann exige la no existencia de Dios para salvar aquello a lo que, a su parecer, no puede renunciarse, a saber, la dignidad del hombre, que en último término consiste en la libertad. Sus reflexiones pueden brevemente reproducirse como sigue: El hombre, de acuerdo con su determinación fundamental, es 'persona moral'. Pero esto sólo lo puede ser, si y en cuanto se decide con libertad. Si hubiera Dios, habría también presciencia divina. Pero la presciencia divina no podría ser puesta en consonancia con la libertad del hombre. Por tanto, tiene que admitirse o presuponerse - precisamente exigirse-_: no hay Dios." La Enciclopedia Cattolica italiana (1949), en el Art. Ateismo, p. 276, col. 2, dice breve y radicalmente: "Atea, no obstante ciertas apariencias de retorno a la ontología tradicional, es la filosofía de Nicolai Hartmann (cfr. en especial la Ética): el juicio de existencia queda en el ámbito de la 'modalidad' y no afecta sino a los entes de experiencia." Paul Hossfeld, por el contrario, sostiene una interpretación más suave: "Como la ética no conoce trasfondos metafísicos, sino que en sus problemas está mucho más cerca de la experiencia que una metafísica en su problema de Dios y en las exigencias de Dios que de ahí se originan, por eso el hecho de que hay un Dios aparece como muy incierto. En todo caso, la ética, por su parte, tiene que rechazar el inmiscuirse de Dios, especialmente como se manifiesta en su providencia y en su salvación. Concluir de ahí con certeza que Hartmann exige inequívoca y expresamente el ateísmo (un ateísmo llamado postulatorio), no es posible, porque junto a semejantes expresiones se encuentran otras que pretenden comprobar muy acentuadamente que no se puede demostrar ni un teísmo ni un ateísmo, y que de la ética con sus problemas no puede originarse algo en favor del teísmo (como todavía pensaba Kant) o del ateísmo. Así, opina además Hartmann, en vista de la disputa sostenida por él entre las exigencias éticas y las religiosas, que puede hallarse aquí también una auténtica aporía, que no es capaz de resolver el pensamiento humano." (Scholastik, 32 [1957], 67-72.) 
apenas se encuentran raras indicaciones, excepto en el Pensamiento teleológico. Pero si se sigue la lectura de las obras en detalle y completamente, se hallan casi en todas, como dije antes, pasajes donde trata una y otra vez el problema, ya inmediata, ya mediatamente en sus presupuestos. Así, existen muy importantes pasajes en la Metafisica del conocimiento, en la Fundamentación de la ontologia, en Posibilidad y realidad, etc. Muchos de estos lugares, es cierto, repiten afirmaciones que básicamente ya se discutieron en la Etica; pero la mayor parte considera el problema precisamente en el plano gnoseológico. De acuerdo con mi investigación el aspecto práctico-ético se estudia de manera casi exclusiva en la Etica y un poco en el Pensamiento teleológico; en cambio, el aspecto teórico y gnoseológico, casi en todas.

Para el conocimiento y juicio cabales de la filosofía de Nicolai Hartmann en este problema, pues, es necesario que este aspecto de su pensamiento sea introducido en la apreciación. Parece injustificable y hasta erróneo que en una crítica no se considere el pensamiento total. Es posible que las afirmaciones gnoseológicas no toquen ni cambien las de la ética, mas el fundamento último de ésta podría sin duda entenderse mejor, si se consideran las convicciones teóricas del filósofo. Quizá no debe decirse que las afirmaciones prácticas dependen, aunque con nexo externo, de las teóricas - como en Kant-; tampoco que las gnoseológicas dependen de las éticas -como precisamente sería el caso de Hartmann-, sino que unas y otras pueden comprenderse en su conexión profunda, para llegar así a una conclusión más o menos definitiva. Aun dentro de la hipótesis de que un aspecto fuera independiente del otro, es necesario tomar noticia de ambos, pues el gnoseológico - precisamente nuestro caso- nos muestra algo nuevo con respecto a la toma de posición del filósofo. Considerando, pues, indispensable estudiar ambos aspectos, la exposición se ocupará primero del tratamiento gnoseológico, y después del ético.

\section{El enfoque teórico-gnoseológico}

La distinción hecha aquí entre el enfoque gnoseológico y el ético, la presenta Hartmann mismo de modo expreso en algunos pasajes. Sin embargo, el tratamiento del problema no responde en general a esta distinción, pues ni dedica escritos determinados a cada uno de estos enfoques, ni deja de tratarlos juntamente en muchos lugares. A pesar de esto, en general puede decirse que, como se entiende de por sí, el enfoque gnoseológico es tocado fundamentalmente en la Metafísica del conocimiento, y el ético, en la Ética:

Los temas discutidos a través del primer enfoque pueden ordenarse de la siguiente manera, adoptando un poco divisiones tradicionales: a) indemostrabilidad de la existencia de Dios en general, indemostrabilidad e irrefutabilidad; b) objeciones comunes contra los argumentos de la existencia de 
Dios, en especial el del antropomorfismo; c) crítica del argumento "ontológico"; d) crítica del argumento por la contingencia; e) crítica del argumento por la teleología universal; $f$ ) crítica del argumento por los grados del ser, por las implicaciones de lo espiritual y personal, y por la necesidad de unidad.

a) Indemostrabilidad de la existencia de Dios en general. Indemostrabilidad $e$ irrefutabilidad

Cuanto Hartmann expresa sobre Dios en el dominio teórico trae el sello del agnosticismo, de la imposibilidad de conocer a Dios y de demostrar su existencia. Todos los argumentos o pruebas en favor de la última son falsos, descansan en prejuicios, ignorancia, ingenuidad, nostalgia y, en el mejor de los casos, en la fe. Todo el pretendido saber acerca de la esencia de Dios es antropomorfismo, apoyado puramente en falsa analogía. El único aspecto positivo, desde cierto ángulo, se refiere a la afirmación, paralela y correspondiente, de la irrefutabilidad de la existencia de Dios, así como a la indicación de que en este problema se halla una auténtica e insoluble antinomia, que sólo podría resolverse en lo irracional. Precisamente porque ésta es la atmósfera, por decirlo así, de las disquisiciones de Hartmann, conviene exponer en primer lugar aquellos desarrollos en donde se sostiene esto en general, o por lo menos se lo acentúa, aun cuando ya sean tratados ahí - y rechazados, naturalmente- algunos de los argumentos en particular.

El grado extremo de la tesis no es sólo el no saber, comprobado simplemente como un hecho, sino el no poder saber, referido a la incapacidad por principio. Ese no saber lo refiere Hartmann tanto a la existencia de Dios, como a su esencia, a su ser personal, a sus atributos más importantes en relación con el hombre, la providencia, la predestinación, etc. Diversos por el marco de referencia o por la base y forma de razonar, todos los argumentos del filósofo, sin embargo, coinciden en sostener la inmanencia del conocimiento, el carácter ideal, especulativo, infundado y fantasioso de afirmaciones al margen o contra la experiencia, y el contraste respecto de la seguridad con que conocemos las cosas humanas. Aun cuando todas las disquisiciones se mueven básicamente en el plano gnoseológico, como se dijo al principio, sin embargo, el punto de partida es a veces ontológico, a veces psicológico-racional, a veces específico de teoría del conocimiento. ${ }^{3}$

Es fácil advertir que de la incapacidad de la razón para demostrar la

3. [Advertencia. La traducción de los textos citados fue hecha directamente por el autor de este artículo. De él provienen también todas las cursivas, excepto algún caso aislado. Las referencias se hacen a las obras originales en alemán, cuyos títulos y ediciones son como sigue (entre paréntesis van antepuestas las abreviaturas con que se las cita al final de los textos reproducidos en las notas):

(ME) Grundzüge einer Metaphysik der Erkenntnis. Vierte Auflage. Berlin 1949. Walter de Gruyter \& Co. 
existencia de Dios y conocer su esencia se sigue lógicamente la imposibilidad de refutarlas, pues las proposiciones pertenecen al mismo plano. En otras palabras, de la indemostrabilidad se sigue la irrefutabilidad. Hartmann, por tanto, no hace sino sacar la consecuencia necesaria, cuando sostiene que ninguna afirmación respecto de lo divino puede refutarse, pues, de admitir esto último, aceptaría fundamentos para la refutación; pero estos fundamentos serían los mismos que para la demostración: es decir, se les atribuiría validez para el conocimiento objetivo-fenoménico en favor de una tesis o de su contradictoria, validez que niega precisamente todo agnosticismo. Si Hartmann no procediera así en el campo teórico, toda su argumentación se desvirtuaría y su pensamiento sería tachado con razón como prejuicioso.

Por otra parte, en la esfera teórica Hartmann deja abierta la posibilidad de que exista efectivamente un ser divino; él no dice: Dios no existe; sino: nosotros no sabemos nada de Dios, ni de su esencia ni de su existencia, y no podemos saber nada; habla de nuestro conocer y dice que éste no puede alcanzar a Dios. La posibilidad de su existencia la expresa Hartmann, por ejemplo, con las palabras: "es posible que se dé una providencia divina". Por tanto, en el plano gnoseológico queda abierto el problema de si existe Dios. Esto se conecta lógicamente con su afirmación sobre la irrefutabilidad de tal existencia. Si permanecemos en la esfera teórica, la razón humana es también incapaz de demostrar que Dios no existe, es decir, de refutar su existencia. No obstante, toda disquisición teórica sobre este problema es para

(E) Ethik. 4. unveränderte Auflage. Berlin 1962. Walter de Gruyter \& Co,

(PgS) Das Problem des geistigen Seins. Zweite Auflage. 1949 Walter de Gruyter \& Co. Berlin.

(GO) Zur Grundlegung der Ontologie. Dritte Auflage. 1948. Westkulturverlag Anton Hain. Meisenheim an Glan.

(MW) Möglichkeit und Wirklichkeit. Zweite Auflage. 1949. Westkulturverlag Anton Hain. Meisenheim an Glan.

(ArW) Der Aufbau der realen Welt. Zweite Auflage. 1949. Westkulturverlag Anton Hain. Meisenheim an Glan.

(TD) Teleologisches Denken. Walter de Gruyter \& Co. Berlin 1951.]

“...sobre el mundo y sobre el fundamento del mundo no podemos saber nada que sobrepase la experiencia..." (GO, 1. K., a, 39.) "Sobre la esencia de Dios nosotros no sabemos nada, y sólo podemos ponérnosla ante los ojos según las relaciones categoriales que dominan nuestro pensar e intuir, pero jamás fuera de ellas o en oposición a ellas." (E, 25, K., C, 244.) "La sobreestimación de lo eterno e imperecedero es nostalgia ciega, que no sabe lo que anhela, no lo conoce y se lo pinta arbitrariamente. Lo proyecta hacia el infinito, hacia lo trascendente, a donde no alcanza conocimiento alguno." (GO, $50 . \mathrm{K}$., d, 317.) "Ni para el ser de Dios, ni tampoco para la sustancia del alma, se pueden mostrar puntos firmes de apoyo en la esfera fenoménica teórica." (ME, 32. K., b 242.) "Nosotros no sabemos si se da tal ser personal [Dios] o aun sólo si se puede dar..." (E, 24. K., d, 234.) "Es posible que se dé una providencia de Dios o no _nadie lo sabe y nadie lo demostrará jamás-, pero sí sabemos nosotros que se da una providencia del hombre. $Y$ del mismo modo una predestinación del hombre." (E, 20. K., e, 199.) Cfr. también: PgS, 2. K., h, 54; $M E$, 33. K., a, 249; 17, K., h, 150; 41. K., a, 312; E, 25. K., e, 248-9; 66. K., b, 633; 85. K., 811 . 
él mero pensamiento especulativo, en el cual no puede demostrarse ni è pro ni el contra. Es también el campo de las auténticas y, por lo mismo, insalubles antinomias, y de lo irracional, del más allá sobre la razón humana. Puede, por tanto, concluirse que para Hartmann la existencia y, aún más, la esencia de Dios, permanecen inalcanzables para nuestra razón. ${ }^{4}$

b) Objeciones generales contra los argumentos de la existencia de Dios, en especial el del antropomorfismo

Para Hartmann todas las pruebas de la existencia de Dios parten de trasfondos. El fundamento al respecto podemos concluirlo del párrafo anterior y de su posición general. En esas pruebas no se da un auténtico comienzo para el verdadero filosofar, para el conocimiento real y objetivo. No se tienen a la mano ningunos fenómenos, ningunos hechos experimentales de la existencia y de la esencia de Dios. Aquellos fenómenos que parecen apuntar hacia ahí, son precisamente sólo aparentes: si se los considera más de cerca y se los analiza más a fondo, se encuentra que su causa no es Dios o su manifestación auténtica y específica, sino algo diverso, y esto pueden serlo muchas cosas. En las pruebas de la existencia de Dios, según Hartmann, el énfasis no está en el fenómeno, sino en el interés del hombre, en la proyección de sus necesidades, deseos e ideales. El hombre quiere demostrarla y llama en su ayuda a determinados fenómenos. $\mathrm{Y}$ es que le importa mucho demostrar esa existencia. En efecto, él necesita a Dios a fin de resolver problemas que de otro modo no sabe resolver; para tranquilizarse ante fuerzas, elementos y poderes, de los que no puede ser dueño; para llenar su vida con esperanzas, que de otro modo no tendrían ningún objetivo real. Dios, por tanto, se podría decir así, tiene que existir; el hombre lo necesita incondicionadamente, pues de otro modo está solo y perdido, es impotente, incapaz, ciego, etc.

Pero toda la situación, toda la problemática desde la que el hombre parte, está falsamente planteada; si analiza las cosas con más exactitud, verá que a partir de esos hechos no necesita a Dios, o que Él no puede ser demos.

4 (Una ontología "crítica") "puede tan poco demostrar que se da un "captar de lo existente en si", como puede demostrar que Dios existe. Es más, tan poco puede demostrar ambas cosas como refutarlas." (ME, Einl., 7.) "Pero de este estado de cosas no se sigue en manera alguna que no se dé una libertad de la voluntad -como tampoco se sigue de ahi la no existencia de Dios;" (E, 73. K., C, 701.) "Las demostraciones de la existencia de Dios aparecieron como falsas, pero sería ridículo por esa razón considerar refutada la existencia de Dios." ( $E$, 75. K., a, 719:) "La existencia de Dios no es en nada más demostrable $-y$ en nada más refutable..." (E, 85. K., c, 817.) “...todas las hipótesis puramente especulativas [como la de algo racional de un orden superior]... son tan indemostrables como irrefutables. No son en nada más ciertas que su contrario, de ellas vale el aserto escéptico ov̉ $\mu \tilde{\alpha} \lambda \lambda$ ov." (ME, 41. K., a, 311.) Cfr. también: $G O, 1$. K., a, 40; 26. K., b-c, 173 . 
trado a partir de esos fenómenos. Detrás de las pruebas de la existencia de Dios se hallan unas veces ignorancia y temor, mitología e inconciencia; otras, nostalgia y esperanza, deseo e inclinación. Pero todo procede del hombre, es decir, él se crea mediante sus capacidades y fuerzas, con sus propias facultades representativas y con sus conceptos, una imagen de aquello que necesita. La empresa entera es, total y absolutamente, antropomorfismo. Según el punto de vista de Hartmann se podrían invertir las palabras de la Escritura: "Y el hombre creó a Dios según su propia imagen y según su propia semejanza." Todas las pruebas de la existencia de Dios son pensadas y conștruidas antropomórficamente: Hartmann repite este reproche casi en todos los pasajes en los que critica y rechaza las pruebas de la existencia de Dios. ${ }^{5}$

\section{c) Crítica del argumento "ontológico"}

La prueba "ontológica" de la existencia de Dios, naturalmente, es también rechazada por Hartmann -como lo es por Kant y por todos los filósofos realistas. La breve descripción de sus elementos es hecha según las concepciones de San Anselmo y de Descartes. El fundamento de su rechazo es el mismo que en los otrós filósofos que repudian este argumento: la conclusión desde la essentia a la existentia, la consecuencia desde el concepto a la realidad.

Como antecedente de su posición, Hartmann reconoce que los filósofos medievales ya habían advertido dónde estaba la falla del argumento. Pero le atribuye erróneamente $\longrightarrow$ con cierto prejuicio desde sus propios puntos de vista- un papel y una preponderancia que no tuvo en la realidad, por lo menos dentro de las grandes direcciones realistas. Porque, si bien es cierto que el problema del "ser supremo" se encuentra ya en el fondo de todo esfuerzo por demostrar la existencia de Dios, sin embargo, el argumento al

5 “.... (el) concepto teleológico de Dios es en todo la fiel reproducción del hombre, sólo que elevada a lo absoluto. Supuesto que la providencia y la predestinación son concebidas como elevadas, infinitas, perfectas (mens infinita, ratio perfecta), Dios en cuanto vehículo de los fines mundanos es en todo la proyección del ser humano-personal elevado por encima de lo humano y cósmico...: toda teleología de la naturaleza, del ser y del mundo es necesariamente antropomorfismo." (E, 21. K., b, 203.) "La conciencia de la libertad se halla, como la conciencia de Dios, bajo la particular sospecha de jurar por una toma de partido no objetiva. Pues en ambos casos el interés más actual del hombre depende de la cosa para la que el fenómeno es tomado como testimonio." (E, 73. K., d, 701.) Lo que el hombre "no entiende, o lo que no puede aprobar desde puntos de vista humanos, lo puede siempre aún atribuir al poder de una sabiduría superior, de una ulterior planificación y fijación de fines... Esta teologia teleológica es radicalmente antropomórfica". (TD, 4. K., a, 36-37.) Ciertas concepciones racionalistas-idealistas "recuerdan directamente la mitologia de los antiguos, quienes sólo podian imaginarse las leyes de la naturaleza como dadas por una razón universal. Lo mitologico en la filosofía aun no ha desaparecido, el idealismo lleva al antropomorfismo en la sangre". (ME, 41. K., b, 319.) Cfr. también: $M E$, 7. K., e, 86-87; 41. K., a, 311; 63. K., c, 491; E, 21. K., 206; $M W$, 44. K., b, 344; $A r W$, 7. K., c, 90; 8. K. b, 96; TD, 3. K., a, 28; 8. K., d, 83; 9. K., d, 96; 11. K., a, 107 . 
respecto no fue "simplemente" el ontológico: más bien éste podría ser considerado casi como una excepción y, en la mayor parte de los representantes, a modo de adición dentro de circunstancias especiales, como precisamente ocurrió en San Anselmo. ${ }^{6}$

Con relación a esta misma prueba se da en Hartmann otro aspecto de interés, que se puede considerar como una profundización del análisis del argumento y que está en relación especial con las disquisiciones cartesianas. La fórmula bajo la cual Hartmann analiza sobre todo este argumento, no se refiere al concepto de Dios, sino más bien a la conciencia de Él, a la conciencia de lo divino, que ulteriormente es admitida como un factum, como un fenómeno; es decir, incluso el concepto de Dios como existente en nuestra conciencia es un factum, algo real, algo dado. $\mathrm{Y}$ aún más: a esta conciencia, a este fenómeno corresponde también otra cosa real; pero el problema en el caso de la conciencia de Dios es precisamente éste: si la realidad correspondiente es Él o más bien alguna otra cosa. Ahora bien, El no puede ser dado como contenido de una conciencia, como correlato de un fenómeno. Por tanto, la realidad correspondiente al concepto o conciencia de Dios, no puede ser un Dios existente realmente. Adviértase aquí, pues, cómo la argumentación de Hartmann presenta la novedad de enfocar el aspecto psicológico, es decir, el carácter de forma y acto de la conciencia o concepto, y el de una conexión externa, formal y analógica, con una realidad determinante, en lugar de destacar el contenido o la intentio de los mismos. ${ }^{7}$

\section{d) Critica del argumento por la contingencia}

La crítica y refutación de la prueba en favor de la existencia de Dios a partir del carácter contingente del mundo - llamado también argumento "cosmológico"- ocupa en la filosofía de Hartmann un lugar muy especial. La

6 Cfr. GO, 19. K., a, 134; 6. K., c, 65. "Esta es_dice- la razón de por qué en el problema del 'ser supremo' la demostración de su 'existencia' siempre ha constituido el punto central, y el argumento que trató de conducir a él, se llamó simplemente 'ontológico'. Con una divinidad que existe en forma meramente ideal se atendió tan poco al sen. timiento piadoso como a la metafísica." (GO, 5o. K., d, 317.)

7 "...en la prueba ontológica de la existencia de Dios el fundamento del factum de un concepto y de una conciencia de Dios, no necesita ser la divinidad existente. Si ésta tuviera que ser por necesidad el fundamento, la prueba serfa correcta y la existencia de Dios demostrable. Aquí la teoria del conocimiento llegó desde hace mucho al trasfondo del error de raciocinio." ( $E, 76 . \mathrm{K} ., \mathrm{c}, 721$.$) "Esto recuerda de manera chocante la$ vieja conclusio de la essentia a la existentia, como la incluye la conocida prueba ontológica de la existencia de Dios; porque se da un concepto del ser perfectísimo, tiene que darse también el mismo ser perfectísimo. Indudablemente hay una diferencia entre fenómeno y concepto. Pero entre una conclusión ontológica a partir de un fenómeno y una conclusión a partir de un concepto, no hay en principio absolutamente ninguna diferencia. Tanto el fenómeno como el concepto no involucran el ser real. Así la libertad como Dios no son dados, pero ambos se entienden como algo real. $Y$ finalmente, atrás del concepto 
causa es que guarda estrecha relación con todo su pensamiento, pero en especial con su doctrina de la modalidad, que es expuesta fundamentalmente en su gran obra Posibilidad y realidad. Como es bien sabido, se trata de una teoría sutil y profunda, en la que no se puede entrar aquí sino en forma sumaria y en cuanto tiene conexión con el tema estudiado en este trabajo.

Las disquisiciones de Hartmann parten del análisis de los modos de la contingencia y la necesariedad, así como de las consecuencias que ambos implican. En la aplicación que hace de su doctrina al problema de la existencia de Dios, Hartmann señala en primer lugar las características que se derivan inmediatamente de sus propios conceptos de necesario y contingente en relación al problema: lo necesario tiene relatividad externa, por lo que se autosuprime y es limitado por lo contingente; éste en cambio es relativo sólo de manera interna, no se autosuprime ni limita, y no implica necesariedad alguna. Enseguida presenta dos tipos de la argumentación tradicional, a cuyo propósito debe advertirse, como algo de gran importancia, que Hartmann atribuye a dicha demostración partir en realidad de lo necesario y no de lo contingente. Además, en esa operación Hartmann procede de modo muy sumario, y expone esos argumentos empleando su propia terminología, en la cual se encierra ya la nueva significación introducida por él. Es in. dispensable mantener esto ante los ojos, porque, por una parte, el sentido y la finalidad de la crítica de Hartmann contra esta demostración de la existencia de Dios puede así ser entendida y valorada correctamente, y por otra, sus objeciones pueden contestarse en forma satisfactoria, por lo menos en el plano lógico, señalando las distinciones pertinentes. ${ }^{8}$

de Dios está escondido no otra cosa que un fenómeno, el fenómeno de la conciencia de Dios. A ésta no se le puede negar la justificación, como tampoco a la conciencia de la libertad. Pero ambas son solamente hechos de la conciencia; de ellos no se sigue en manera alguna la realidad del contenido que se entendio." (E, 73. K., c, 700.) Cfr. también: Ibid., d, 7o1.

8 "La necesariedad lleva consigo el principio de su autosupresión e implica con ello a la contingencia como su limitación; la contingencia, por el contrario, no conoce ninguna autosupresión ni limitación, no implica de por sí ninguna necesariedad. Autosupresión, precisamente, es la consecuencia de la externa relatividad a la realidad. La contingencia, en cambio, tiene sólo relatividad interna, no externa... El gran ejemplo [del desconocimiento de esos principios] es el tremendo pseudoconcepto del 'ser absolutamente necesario'. Con èl se entendia a Dios como el primer principio de toda necesariedad existente en el mundo." "Dos tipos de reflexión hablan en favor del absoluto ser-necesario de este primer principio: la una es la contenida en la mayoría de las formas de la demostración cosmológica de la existencia de Dios. Concluye así: un fundamento sobre el que se apoya la necesariedad de algo, tiene él mismo que ser necesario; por tanto, lo que como fundamento primero de todos los fundamentos es al mismo tiempo fundamento de toda necesariedad en el mundo, ha de tener absoluta necesariedad; de otro modo se desplomaria toda necesariedad, sería necesariedad contingente. $Y$ la segunda reflexión procede más o menos así: si todo lo necesario es consecuencia de un principio, también el principio es, por su parte, necesario para la consecuencia; ahora bien, si la serie de los principios retrocede más atrás, entonces su necesariedad tiene que volverse cada vez más incondicionada; el principio de todos los principios, por consiguiente, tiene que ser principio absolutamente necesario." ( $M W$, 10. K., b, 91-92.) 
En cuanto a la refutación de esos argumentos, hecha ahí mismo - también sumaria, pues en el pasaje se trata sólo de la aplicación de los principios a un "gran ejemplo"-, puede observarse no sólo que Hartmann toma las categorías de necesariedad, realidad y contingencia en un sentido particular y propio, sino que el procedimiento de la demostración parece arreglado de antemano y pretende entenderlo en forma que la demostración tradicional efectivamente no demuestre. Se podría uno preguntar, de quién es la formulación y la secuencia de este argumento que Hartmann tiene ante los ojos, pues en verdad no es ni la más clara, ni la radical y general. También debería decirse que él expone éstos sus argumentos, en apoyo de la tesis principal, de manera que la solución está ya casi a la vista según el sentido de su terminología. Pero más importante que todo lo anterior es que en la refutación del filósofo salta a la vista un tránsito del plano estrictamente ontológico en que se mueve la prueba tradicional al plano específicamente lógico-gnoseológico. $Y$ esto parece tanto menos explicable, cuanto que ahí mismo Hartmann hace una distinción semejante.?

En un último momento de la refutación, la consecuencia inmediata de ésta es establecida atendiendo al propósito final de toda la demostración. Hartmann la expone en forma radical y declara que, según él, el resultado es precisamente contrario al que se buscaba, pues Dios, si se lo presenta como el ser absolutamente necesario, será justo por ello el ser absolutamente contingente; la razón es que un ser necesario por si viene a ser más bien un ser no-necesario. A través de toda la refutación, como puede verse en los textos, Hartmann ha invertido no sólo los conceptos y el punto de partida, sino también la dirección entre necesario y contingente, pues ahora el primero necesita del segundo y se explica por él, mas no a la inversa. En suma, a propósito de lo que Hartmann argumenta contra la prueba "cosmológica", se tiene que atender sobre todo a la forma en que el filósofo toma algunos términos y expresiones, pues de otro modo se hallarian en él contradicciones

9 "Ambas reflexiones son falsas. La primera concluye a contingentia mundi --porque, de otra manera, el mundo junto con toda su necesariedad sería, a pesar de todo, contingente en el fondo'. Este temor ante lo contingente es comprensible, pero no se puede argumentar desde él. Por lo demás, aquí ocurre un simple malentendido del serprincipio. Ser principio de algo no significa en absoluto ser necesario, sino solamente sacar de sí una consecuencia necesaria. En la relación entre principio y consecuencia sólo la consecuencia es absolutamente necesaria (con base en el principio), pero jamás el principio mismo. Para el ser-necesario de la consecuencia, en cambio, basta, como se demostró arriba, el ser-real del principio. Un principio primero de toda consecuencia necesaria en el mundo, por tanto, no tiene que ser en absoluto un principio necesario, ni mucho menos uno 'absolutamente necesario'. Basta que sea un principio real. La segunda reflexión, empero - que la mayoría de las veces se halla en el fondo y se descubre sólo ocasionalmente-, confunde la indisperasabilidad del principio para la consecuencia con la necesariedad del principio mismo. En efecto, aquella indispensabilidad es, en el mejor de los casos, fundamento conocitivo de la reflexión, pero luego, en todo caso, no es fundamento entitativo de la cosa." (MW, 10. K., c, 92-3.) 
abiertas y expresas. Porque, después de seguir su razonamiento, se tiene la convicción de que Hartmann emplea un lenguaje diferente al de los filósofos que sustentan la validez del argumento cosmológico, pues, se podría decir, muchas cosas que Hartmann sostiene, las afirmarian ellos también en sus propios términos, y aun el mismo Hartmann no diría muchas cosas, si estuvieran expresadas en los términos de aquéllos. ${ }^{10}$

\section{e) Crítica del argumento por la teleologia universal}

A la demostración que parte de la teleología universal - llamada tam. bién argumento "físico-teológico"- Hartmann dedica la mayor atención y también el espacio más amplio en sus obras, es más, le consagra una obra entera, la titulada Pensamiento teleológico. Si pregunta uno la razón de por qué pone sobre esto tan grande énfasis, debe responderse que para Hartmann esta demostración reviste los siguientes caracteres: primero, es la más universal, pues ya desde los comienzos, no sólo del filosofar, sino de la concepción humana del mundo, la pensaron los hombres; segundo, es la que está más profundamente enraizada en el espíritu y en el alma humanos, como convicción interna respecto del orden y de la armonía del universo; tercero, es la más evidente, la más fácil y verosímil, de manera que casi para todo mundo es accesible; cuarto, es la más popular, ingenua y errónea, al grado que casi se presupone lo que se quiere probar; quinto, es la que está más construida y orientada desde lo humano, en forma que le corresponde a ella primariamente y con todo derecho la designación de antropomorfismo. Hartmann funda el rechazo de este argumento en un análisis profundo, sutil e incluso refinado - análisis categorial - del nexo final, análisis en el que tampoco es posible entrar a fondo aquí, porque sólo en su consecuencia última y más importante toca la demostración de la existencia de Dios. Esa última consecuencia se refiere a que en la naturaleza, en el mundo -fuera del dominio humano- no se dan en realidad procesos finales ningunos y que en todo caso a la finalidad (realizada $u$ objetiva) que pudiera considerarse presente ahí, no corresponde ninguna actividad final, consciente y personal. Pero,

10 'Aplicado esto, pues, al 'ser absolutamente necesario', significa nada menos que, antes bien, es en verdad el 'ser absolutamente contingente'. De otra manera, puesto que constituye el límite de la relacionalidad del mundo, tendría que ser un ser necesario por sí mismo. Y precisamente esto es lo que se ha querido decir con la expresión causa sui. Pero, en verdad, un ser necesario por si significa un ser no necesario. Pues la necesariedad tiene en sí indudablemente la 'relatividad externa'. Pero aquí no existe nada fuera de él, 'con fundamento en el cual' pudiera ser necesario. Que se diga, pues, enhorabuena que tiene su fundamento en sí, que es causa sui; con ello no se gana en modo alguno modalidad superior. Pues precisamente, lo que tiene el fundamento en sí, sin duda no lo tiene por eso fuera de sí; por tanto, no es algo necesario, sino algo contingente. Dios en cuanto ser absolutamente necesario es más bien el ser absolutamente contingente." ( $M W$, 10. K., b-c, 93-4.) 
junto a esta razón profunda y última, o en parte como traslación de ésta a un plano no tan estricto, Hartmann emplea para el rechazo del argumento la objeción del antropomorfismo, de la mitología, de la concepción ingenua del mundo, etc. En los pasajes más importantes donde Hartmann trata el tema, califica esa actitud metafísica como teleologismo, es decir, teleología universal; pero además, como variante, hay una "teleología del todo", que también podría llamarse teleología unitaria. ${ }^{11}$

f) Critica del argumento por los grados del ser, por las implicaciones de lo espiritual y personal, y por la necesidad de unidad

Las tres pruebas de la existencia de un ser divino (super-ser, espíritu suprahumano, persona de un orden superior, principio absoluto unificador) reunidas aqui, lo han sido no sólo por el punto de partida semejante o co mún, sino también porque con frecuencia Hartmann las trata juntamente. En especial las que se basan en los fenómenos espirituales y personales se diferencian en realidad sólo por el énfasis sobre el uno o el otro aspecto, y en ambos, por otra parte, está ya la tendencia, es más, la presuposición de lo unitario. Aun cuando se dan algunas diferencias entre la prueba con base en los grados del ser rechazada aquí por Hartmann y la clásica escolástica por los grados de perfección, no obstante, puede decirse que coinciden en el aspecto Iógico formal.

Como objeciones contra este argumento, o bien como punto de partida para su rechazo, Hartmann repite sobre todo los motivos del antropomorfismo, de la mitología, de la tendencia a concepciones del mundo, del sentimiento religioso, etc. La refutación filosófica fundamental, empero, sostiene esto: que es una hipótesis fenoménicamente infundada, sólo analógica y con carácter especulativo e ideal, tanto inferir, partiendo de los fenómenos del conocimiento humano, un intellectus infinitus, intuitivus, archetypus, y des-

11 “... se atribuye al mundo, entendido como unidad, un principio supremo, motor o creador, que como lo absoluto, como principio del mundo o deidad, produce, operando finalmente, la multiplicidad de las formas del ser... En sus formas teológicas y semiteológicas (entre las últimas cuentan también los panteísmos), constituye la forma más extendida y popular de la imagen finalista del mundo. Es característico de ella que el telos no es pensado aquí inmanente ni a los procesos ni a las estructuras formales (no como su impulso interno), sino más allá de ellos, 'sobre' ellos, como finalidad trascendente." (TD, Einl, 8-9.) "El concepto filosófico de Dios, se podria decir, es desde un principio por entero teleologia pura; pues está construido sobre la intuición fundamental de que un poder unitario, racional, que destina providentemente, domina en el mundo y todo en él, incluido también el hombre, lo orienta hacia una meta plena de sentido." (TD, 4. K., $a, 3^{6}$.) "... sólo un ser originario pensado como divinidad puede determinar a un mundo dirigido con sentido y finalidad... Por esto el principio que se encierra en el todo del mundo, tiene que ser 'divino'... La simple verdad es: se quiere tener un mundo dispuesto teleológicamente; por eso se busca no un fundamento mundano cualquiera, sino uno divino. Dios es aquí sólo un nombre para el ordenamiento con sentido del mundo." (TD, 4. K., b, 38.) 
pués hipostasiarlo, como postular, partiendo de datos especificos, un espíritu personal consciente, una persona auténtica y real como correlato del mundo en el plano macrocósmico, así como el hombre lo es en el microcósmico. También la crítica y discusión de esta prueba, sobre todo en los argumentos de lo espiritual y personal, ocupan en las obras de Hartmann un gran espacio, cuya razón debe buscarse quizá en el hecho de que el filósofo se encuentra y se siente en determinadas relaciones con el idealismo alemán, por un lado, y con el personalismo de Scheler, por otro. Resulta también de cierta importancia que, en la discusión de los argumentos incluidos aquí, Hartmann haga referencia explícita y directa (cosa no frecuente en él) a pensadores concretos -o direcciones- que sustentan los puntos de vista criticados; así encontramos a Platón, Aristóteles, Kant, Scheler, o el platonismo, la escolástica, el personalismo, etcétera.

El argumento por los grados del ser, criticado por Hartmann, no varía sustancialmente del ordinario empleado por los filósofos teístas. En el pasaje fundamental donde expone dicha prueba la refutación se advierte más bien en el tono; pero en el amplio contexto se invalida el razonamiento con los principios de la ontología hartmanniana, de que modos de ser superiores -en particular el del ser ideal - tienen menos realidad que los inferiores y son "portados" más bien por éstos. ${ }^{12}$

La demostración que parte de principios del mundo espiritual se conecta, como Hartmann mismo lo señala, con el argumento de los grados, porque el espíritu puro o absoluto es el grado supremo; pero aquí el procedimiento demostrativo es directo, prescinde de la gradación y consiste simplemente en un raciocinio por implicación necesaria. En cuanto a sus antecedentes, Hartmann hace un poco de historia, recorriendo a vuelo de pájaro los origenes del concepto implicado en esta demostración. Para ello parte de la doctrina kantiana de la "conciencia trascendental", rastreando las ideas análogas hasta Aristóteles a través de la escolástica y el neoplatonismo.13

12 "Admitamos por un momento que se da un 'ser ideal'; se lo puede entonces entender sin más como el ser 'superior', por ejemplo, como exento de la temporalidad y del carácter perecedero, un ser siempre existente, eterno, divino. Así fue entendido por Platón y por todas las formas posteriores del platonismo. (...) En ambos casos se trata de escalonamientos o grados del ser... En la esfera aristotélica de los grados se vislumbra con claridad algo semejante, aun cuando no es expresado; y por cierto, el grado supremo del ser se halla aquí en el espíritu (voṽs), el infimo en la materia ( $\left(\lambda_{\eta} \eta\right)$... Claramente expresado encontramos esto luego en el neoplatonismo, que degradó la materia hasta el no-ser, y entendió en cambio el espiritu como ser puro, la divinidad como super-ser. En esta forma se mantuvo ese pensamiento en los grandes sistemas de la Edad Media; cuanto más rico es el conjunto de la determinación del ser (de los predicados esenciales positivos), tanto más alto es el grado de realidad. La divinidad como ens realissimum cierra la serie de los grados hacia arriba." (GO, 8. K., c, 74-75.)

13 "Se cree... tener que explicar el mundo o 'desde arriba' o 'desde abajo; se decide uno o por la omnipotencia del espíritu, o por la omnipotencia de la materia. En ello se asienta sin más como absoluto o un ser fundamental espiritual o uno material. (...) Aquellos que procuran hacer justicia a los fenómenos del espiritu, terminan casi todos en un 
El enlace entre el argumento del espíritu y el de la persona resulta ser en el fondo, según los pensadores de esa posición, una consecuencia del segundo respecto del primero. En este argumento, que se basa en el postulado de una persona universal correlativa al mundo, Hartmann critica expresamente el "personalismo metafísico" de Scheler, sin entrar a fondo en la refutación. El argumento de éste procede así: si la correlación entre persona y mundo es válida, tiene que darse una persona universal infinita y absoluta correlativa del macrocosmos, del universo, así como la persona humana lo es del microcosmos. Y Hartmann lo refuta mediante un simple dilema: si Dios existe, es parte del mundo - y no poseerá ya los atributos que lo caracterizan; si Dios no existe, no está frente al mundo ni será su correlato.14

Como se advirtió desde el principio, Hartmann mezcla, o más bien relaciona, unos aspectos de la argumentación con otros. Así, al presentar los anteriores, consideró ya el momento de la unidad, y al poner éste como centro, aludirá al menos a aquéllos. En sustancia, Hartmann sostiene que según este argumento "la necesidad metafísica de unidad" se halla implícita en las preguntas primitivas de la filosofía que buscaban una causa primera, un fundamento de todas las cosas, un fin último, los cuales no podian ser sino únicos, pues la dependencia, como principio de explicación, debe convergir en un punto único: dos principios dejarían insoluto el problema planteado. Ahora bien, ese principio es la divinidad. ${ }^{15}$

concepto de Dios..." (PgS, 3. K., d, 64-65.) Con su teoría de la "conciencia trascendental" Kant "siguió una idea muy vieja, la del intellectus divinus o archetypus, cuyo pensar es al mismo tiempo la creación de los objetos. Sólo le quitó el ropaje teológico-metafísico y puso con ello de manifiesto su contenido de teoría del conocimiento. La idea misma la encontró como herencia de la Edad Media, que a su vez la debia a la metafísica de Aristóteles. Aristóteles habia convertido el 'espiritu' divino en cuanto pensamiento de si mismo en primer motor de todos los procesos, en los cuales se originaba un ser. Haciendo el rodeo por sobre el platonismo posterior, este concepto de espiritu fue identificado con el concepto cristiano-personal de Dios. $\mathrm{Y}$ esta síntesis histórica quedó fijada como prototipo de todas las concepciones posteriores de una persona-espiritu universal." (PgS, 32. K., d, 308.)

14 "A partir de aquí toda filosofia de la relacionalidad con el yo y de la relatividad hacia el mundo se evidencia como un craso malentendido de los fenómenos de lo dado...: 'yo y el mundo' $\longrightarrow$ tal vez 'yo y mi mundo'-, esto es ontológicamente tan desviado como 'Dios y el mundo'. O existe Dios, y entonces pertenece a la totalidad de lo existente, pertenece por tanto al mundo real; o no existe, pero entonces no se halla tampoco frente al mundo." (GO, 37. K., d, 240.) "Si la correlatividad entre persona y mundo permanece en vigor como ley, tiene que darse un miembro personal paralelo al macrocosmos. Tal miembro lo formula la idea 'de una persona espiritual infinita y perfecta'... 'Así, la idea de Dios está dada juntamente con la unidad e identidad y unicidad del mundo en virtud de un nexo esencial.' En estas proposiciones se halla el personalismo metafísico. Scheler tiene por contradictorio sentar como real un único mundo concreto, sin sentar a la vez la idea de un espíritu concreto: no se puede pensar el mundo sin pensar también a Dios." $(E, 25$. K., a, 239-40.)

15 El "postulado del principio supremo" "hace aparecer la necesidad metafísica de unidad en una autonomía mucho mayor" y está "ya contenido en forma latente en la antiquísima pregunta por el 'principio de todas las cosas'... No de otra manera sucede con la pregunta, que siempre retorna, por la 'causa primera', el 'fundamento de todas las cosas', 


\section{El enfoque práctico-ético}

El tratamiento del problema de la existencia de Dios en el plano de la razón práctica supone, como es natural, lo concluido por la razón especulativa. Esto debe aplicarse, por una parte, en un sentido negativo, es decir, a la falta de datos fenoménicos y de cualquier punto de arranque para iniciar el movimiento conocitivo hacia lo trascendente, cosa que Hartmann vuelve a mencionar con frecuencia, inclusive aun dentro del mismo planteamiento práctico. Mas, por otra parte, sobre todo en un sentido positivo, es decir, en lo que se refiere a la seguridad y evidencia de los conocimientos acerca del hombre y de lo humano, de lo dado en el campo de la inmanencia y conocido de manera unívoca, directa y racional. Porque, en efecto, no sólo el enfoque práctico-ético necesita tener bases o contenidos conocidos para establecer sus conclusiones, sino que justo el razonamiento de Hartmann sólo puede concluir en cuanto que, por un lado, la existencia del hombre es un dato firme e indubitable de la experiencia, es algo para cuyo conocimiento se tienen puntos de partida fenoménicos, inmanentes, a fin de constituir con toda validez el carácter objetivo, y por otro, para la existencia de Dios no se tienen tales bases y sólo resulta ser una idea o un concepto, una hipótesis o un postulado.

El planteamiento que se estudia aquí consiste esencialmente en concluir o deducir de las necesidades y exigencias éticas, de las implicaciones y nexos del obrar moral humano, afirmaciones postulatorias, precisamente indirectas y analógicas, sobre la existencia -o más bien no-existencia- de un ser absoluto, infinito y perfecto. Como se advierte, la posición de Hartmann en este punto es específicamente contradictoria de la de Kant y de la de Scheler, pues mientras éstos, aunque por diversas vías, sostienen una deducción o demostración indirecta, "paragnoseológica", digamos, de la existencia de Dios a partir del campo de la ética o de la axiologia, aquél concluye, o se ve precisado a concluir, precisamente desde las características necesarias de los actos morales, que Dios no puede ni debe existir.

Sin embargo, si se observan las cosas más de cerca, puede advertirse que el punto de partida es en cierto respecto también diametralmente opuesto:

el 'fundamento del mundo', asi como por el 'fin último' en imágenes del mundo expresamente teleológicas. Un pensamiento universal de evolución exige categóricamente la unidad del origen, y un teleologismo universal, la unidad del telos. Pero el postulado de unidad en cuanto tal dondequiera es el mismo. Proviene de la convicción no expresada, de que la unidad de un nexo continuo sólo puede darse en el mundo real, cuando todos los miembros y relaciones parciales son dependientes de un punto único. En muchos sistemas el papel del punto de unidad le corresponde a la divinidad." (ArW, 15, K., a, 151-2.) Cfr. también: $M E$, 17. K., a, 150; 41. K., b-c, 312-14; PgS, 2. K., a, 51-52; 3. K., a, 59; 32. K., d-c, 304-7, 309-10; GO, 5. K., d, 62; 23. K., a, 156; 26. K., b, 174; $M W$, 4. K., a, 54; 43. K., a, 333-4; 44. K., b, 344; 53. K., b, 414-15; $A r W, 15$. K., c, 154-55; 32. K., a, 319; 48. K., c, 469 ; TD, 5. K., b, 45; 10 , K., c, 105 . 
Kant y Scheler parten de lo absoluto (de la "aparición" del Absoluto, diría Fichte), es decir, desde la necesidad de lo absoluto, desde ciertas caracteristicas de absolutez manifestadas en el mundo finito; podría decirse, por tanto, que parten de Dios mismo, como en el fondo lo hacen todas las demostraciones de la existencia de Dios. Hartmann, por el contrario, parte del hombre, desde lo humano concreto, desde la necesidad de afirmar simplemente lo finito, relativo y perecedero, desde las características limitadas e imperfectas, que se dan fácticamente, también, en el mundo finito. La admisión de un carácter absoluto de los valores por Hartmann no contradice a la posición anterior, porque en ello sólo se trata de un ser en si ideal, un ser que, más aún, tiene el máximo de entidad ideal, pero el minimo de entidad existente real. Ahora bien, partir de un ser absoluto semejante o establecer conexión con él, según Hartmann, no ofrece ningún fundamento para demostrar la existencia de Dios, porque justo no se trata de algo existente en el mundo real. Desde esta perspectiva podría concluirse, con las precisiones debidas, que las tomas de posición y los razonamientos sobre el problema de Dios afirman en realidad aquello de que parten: si parten del hombre estrictamente en si y aislado, no relacionado - finitud, relatividad, contingencia-, afirmarán al hombre; si parten de Dios —exigencia de infinitud, necesidad de absolutez, implicación de necesariedad-, afirmarán a Dios.

El razonamiento práctico de Hartmann podría sin duda abordarse desde diversos ángulos, partiendo de los aspectos formales-metodológicos o de los temáticos-doctrinales. Sin embargo, entre los varios posibles, el más sugestivo y adecuado parece ser la tensa situación problemática, es más, antinómica, presentada por Hartmann entre el hombre y Dios, entre las exigencias de Dios y las necesidades del hombre, situación que desemboca en un conflicto inevitable y resoluble sólo con la eliminación necesaria de uno de los dos polos. Esa misma situación puede considerarse también como la que ofrece los contenidos de las premisas puestas por el filósofo para su conclusión de la inconveniencia de que Dios exista. El argumento entero puede formularse así: Dios exige dependencia absoluta y el hombre necesita libertad radical; ahora bien, la necesidad de libertad del hombre es un conocimiento cierto y objetivamente fundado, mientras que la exigencia de dependencia es sólo una hipótesis, una inferencia especulativa sin fundamentos reales: luego la hipótesis tiene que desaparecer frente al hecho; porque el contenido de aquélla es contradictorio del de éste. O también en esta forma: la exigencia de Dios choca y destruye la necesidad del hombre; ahora bien, la necesidad del hombre es algo real que existe fenoménica y objetivamente; luego la exigencia de Dios, pura hipótesis, debe rechazarse, considerarse irreal e infundada. Y si se enfoca el problema bajo la distinción de contenido y forma, resulta así: los contenidos de las afirmaciones sobre Dios y el hombre son antitéticos, se eliminan, suprimen e invalidan recíprocamente; respecto a la forma, en cam- 
bio, la afirmación acerca del hombre prevalece y queda sobre la afirmación de Dios, como prevalece la certeza sobre la hipótesis.

De acuerdo con las formulaciones anteriores la exposición puede dividirse en forma aproximada - por cuanto lo permiten los desarrollos textuales mismos de Hartmann- en cuatro párrafos: a) las exigencias de Dios; b) las necesidades del hombre; c) las consecuencias del enfrentamiento entre Dios y el hombre; d) antinomia e indiferencia de la ética en el problema Dios-hombre.

\section{a) Las exigencias de Dios}

Hartmann utiliza algunas veces expresamente el término "exigencia" por parte de Dios, pero en general más bien habla de los "atributos" o "predicados" de la divinidad, que son de donde deriva el derecho de exigir ella del hombre lo que le corresponde. Esos caracteres esenciales son cuatro. Al tratar en un pasaje sobre Los predicados de la divinidad y su limitación, expresa que son los siguientes: libertad, providencia, predestinación, conciencia de los valores. $\mathrm{Y}$ el origen de estos atributos se halla precisamente en las "cuatro determinaciones fundamentales de la persona como ser moral". ${ }^{16}$ Pero no todos estos predicados tienen para Hartmann la misma importancia ni el mismo valor como punto de partida para su argumentación. Haciendo a un lado la libertad y la conciencia valiosa - cuya existencia en Dios no significa nada negativo para el hombre - insistirá en una forma casi desmedida sobre la providencia y la predestinación. ${ }^{17}$ Fácilmente puede advertirse el porqué de la insistencia de Hartmann sobre esos atributos: de ellos dimanan específica y directamente las exigencias de Dios, que el hombre no podrá aceptar - las cuales, por tanto, serán rechazadas, y con ellas sus atributos, y juntamente, en fin, el poseedor de los atributos. Estas exigencias se dirigen, como se verá después, contra el aspecto formal de los caracteres esenciales del hombre: la libertad y la autodeterminación, puesto que la providencia y la predestinación significan un absoluto determinismo, no causal, sino final, que impide por principio aquéllas.

El aspecto material o de contenido de la esencia del hombre es tocado en otro enfoque de esas exigencias y esos atributos de Dios: el que se refiere

$16 \mathrm{PgS},{ }_{15}$ K., a, 163.

17 "Providencia y predestinación son los atributos de la divinidad..." (E, 20. K., f, 199.) "Son los atributos de la divinidad, providencia y predestinación..." (E, 21. K., d, 208.) Dios representa "una providencia real omnipotente..." (E, 66. K., b, 633.) La providencia divina "es teleológicamente un determinismo final... [En éste] la fuerza determinante es infinita y todopoderosa". $\left(E, 8_{5}\right.$. K., 814.) "La teleología ... es atributo de la divinidad..., la predeterminación, la predestinación... [Dios es] un ser que todo lo predestina." $(E, 36$. $\mathrm{K} ., \mathrm{h}, 359$.$) Hay un "determinismo final de la providencia divina..." (E, 85. K., 815.) A$ Dios se atribuye "providencia y omnipotencia...; [Dios es un] ser omnipotente y omnisciente..." (E, 66. K., a, 631.) 
a los valores morales, a la moralidad, y va directamente contra la conciencia de los valores en el hombre, pues en vez de reconocerlos como tales, los recibirá como mandamientos divinos; los valores son valores porque Dios lo quiere o lo ordena. Pero también se dirige ese aspecto contra la autodeterminación, ya que no puede hablarse estricta y radicalmente de ésta cuando los valores son heterónomos. Hartmann afirma repetida e inequívocamente que de los atributos, y aun de la esencia de Dios, dimana la conversión de los valores en mandatos. ${ }^{18}$

Casi en todos los pasajes en que Hartmann enfoca así este problema señala que la conversión aludida proviene de la actitud religiosa: esto es com. prensible, y cierto además, pues efectivamente todas las religiones han enseñado esa doctrina y ella es derivación natural de sus principios. Pero es importante también advertir esto, porque Hartmann contrapone la actitud religiosa a la actitud ética, destacando que aquélla está en favor de Dios y ésta en favor del hombre. ${ }^{19}$

Muy ocasionalmente menciona Hartmann otras acciones de Dios, secundarias o derivadas, respecto del hombre, u otros atributos, como la infinitud, la omnipotencia, la omnisciencia, etc. Dos atribuciones, sin embargo, merecen atenderse especialmente por la conexión con el sentido general de su tesis. La primera y más importante se refiere a la redención, cuyo planteamiento sólo puede hacerse desde el campo religioso. La culpa moral, en efecto, entendida como pecado, como ofensa infinita, exige necesariamente ser lavada por obra de Dios mismo, ser infinito. ${ }^{20}$ La segunda atribución, o más bien

18 "El hombre religioso atribuye a la divinidad todo aquello de lo que no conoce el origen; así en primera línea el origen de los mandatos morales. Mas por ese medio desconoce el carácter autónomo de los valores morales." (E, 7. K., c, 68.) "El pensamiento mítico-religioso atribuyó a Dios desde siempre toda fuerza, así como también entendió los valores como sus mandatos." (E, 20. K., f, 199.) "La representación religiosa es precisamente que Dios no sólo domina previendo en la ley natural, sino que también habla de manera inmediata en los mandatos morales. El es el legislador, el hombre en cambio es aquel a quien se dirige el mandato." ( $E$, 73. K., d, 693.)

19 "A esta tesis le opone la religión la antítesis: toda exigencia moral de deber es en el fondo mandato de Dios, expresión de su voluntad, y sólo por este motivo el hombre, a quien se dirige el mandato, experimenta su contenido como valor moral. Pues la moralidad consiste en la vida según el mandato de Dios. En virtud de esto los valores morales se vuelven dependientes, heterónomos. Pues precisamente han sido dados, por decisión soberana de Dios... Es indiferente qué dirección se dé a esta idea. Si se dice 'Dios manda lo que es bueno', o 'Dios es el bien', o 'En el valor de Dios (de lo santo) como el valor absolutamente supremo están fundados todos los valores morales' -_esto no constituye ninguna diferencia para la heteronomía de los valores. (...) Está en la esencia de Dios que en un mundo, que es su pensamiento y su obra, no puede haber nada valioso sino porque él lo quiere, ordena, o porque de alguna otra manera se sigue de su esencia, supuesto que sólo por ese medio tiene la fuerza de un deber-ser. $Y$ si se dieran ahi junto valores subsistentes en sí, Dios tendría que o negarlos o sólo sancionarlos con su voluntad." ( $E$, 85. K., 813.)

20 "La conducta religiosa del hombre hacia Dios no está agotada ni con su de - endencia providencial de Dios ni con su capacidad de pecar ante Dios; culmina sólo en su redención por Dios con respecto al 'pecado". Pecado es la misma culpa moral de la que también habla la ética, pero no 'como' culpa moral, es decir, no como culpa ante el foro de la pro- 
atributo, que vendría a ser la esencia misma de Dios según la tesis de Scheler, citado en el pasaje, se plantea filosóficamente; en ella también se da margen, aunque de modo indirecto, para encontrar una exigencia de dependencia al hombre por parte de Dios. Se trata de lo santo, de la santidad, valor supremo sólo atribuible a Dios, mientras los valores más bajos corresponden únicamente al hombre. ${ }^{21}$

Dos observaciones cabe aún hacer aquí: primera, que la asignación de atributos a la divinidad por Hartmann, y aun toda su posible concepción acerca de Dios, está tomada fundamentalmente de las ideas religiosas $\mathrm{y}$, en parte muy pequeña, teológicas del cristianismo; especulaciones específicas suyas no las hay, ni teológica ni filosóficamente - cosa comprensible y justificada, pues su actitud es negativa, no positiva. Segunda, que aun cuando algunas veces Hartmann habla del mundo y de la naturaleza -incluido sin duda el hombre- como obra de Dios, e igualmente del creador y de la creación, no menciona ésta nunca como atributo, ni tampoco la exigencia de dependencia radical que de ahí derivaria para el hombre como creatura: esto, por una parte, parece un tanto extraño, pues ahí estaría el último fundamento de las exigencias de Dios; mas, por otra parte, resulta sintomático de acuerdo con su doctrina, ya que la creación por parte de Dios, y el carácter de creatura por parte del hombre, plantearían serias dificultades a su pensamiento.

\section{b) Las necesidades del hombre}

Hay una idea que predomina en casi todas las referencias de Hartmann a los caracteres esenciales del hombre (dentro del problema que nos ocupa), los cuales son el fundamento interno de sus necesidades: que ellos son precisamente los mismos atributos de la divinidad, idénticos en su contenido esencial, aunque no en su modo de ser; la única diferencia entre ambos, como atributos de Dios y características del hombre, es la perfección, la absolutez, la infinitud. No es difícil encontrarle a esta tesis hartmanniana sus puntos de referencia y explicación. En primer lugar se ofrece su crítica del antropomorfismo, el cual se basa en una proyección de las facultades y acciones humanas: lo divino, por tanto, no es en el fondo sino lo humano, pero elevado a lo absoluto, a lo infinito. En segundo lugar aparece su humanismo, que

pia conciencia y de los valores, sino ante Dios... Y aqui estd el punto de arranque para la obra de Dios en el hombre, la redencion." (E, 85, K., 817.)

21 "Si se dan personas de orden superior, es natural admitir --puesto que las personas son portadoras de los valores morales- que los valores superiores corresponden a personas de prden superior: el valor supremo, por tanto, sólo correspionde a Dios; al hombre, en cambio, sólo los valores morales más bajos. De hecho Scheler vislumbra en lo 'santo' un valor supremo semejante, cuya superioridad sobre todos los otros valores - y no sólo los éticosdebe enraizarse incluso en una relación objetiva de fundamentación." (E, 25. K., 2, 249.) 
en la constitución de los caracteres de ambos implica un movimiento de ascenso desde el hombre hasta Dios, y no de descenso desde Dios hasta el hombre. En tercer lugar se presenta el agnosticismo, es decir, la inmanencia del conocimiento, de donde procede que bases firmes y ciertas sólo se tengan para conocer las cosas humanas, y no así para las supuestas divinas. Pero casi siempre, en cuanto dice el filósofo al respecto, se advierte una indisposición hacia todo lo divino y un rechazo de demostraciones o afirmaciones sobre Dios: actitud negativa que se justifica si Dios, en resumidas cuentas, no es, con relación al hombre, sino una falsa analogía en el aspecto formal, y en el material, una verdadera identidad. Porque entonces no ofrecerá ningún problema negar una divinidad que no lo es, sino cuando más un ser humano ideal. Aquí es donde se ve de una manera directa y expresa el humanismo hartmanniano.

Antes de exponer el pensamiento de la identidad es oportuno considerar la misión y función que Hartmann atribuye a la ética -de la cual, sin embargo, no queda ajena la identificación del hombre con Dios, la divinización de aquél. Si la religión vindica los derechos de Dios, la ética defenderá los derechos del hombre. La ética llega a ser la constitutora del hombre y la que señala sus ideales y su destino. Es su llamamiento para colaborar en la obra de la creación. Es su abogado y protector en la empresa de reivindicar sus derechos, su dignidad, su posición. Ella se encargará de hacer que le devuelvan al hombre, que recupere lo que él mismo, por ignorancia o cobardía, había entregado precisamente a Dios. De las palabras del filósofo puede deducirse además un eticismo axiológico. Dejando aparte el aspecto polémico ateísta, debe reconocerse en los sentimientos y las enseñanzas de Hartmann una gran elevación de miras, un noble propósito de hacer tomar al hombre plena conciencia de sí mismo y una recta intención de llevarlo a realizar fe. cundamente los valores. ${ }^{22}$

Puede decirse que la asignación al hombre, hecha por Hartmann, de los

22 "...la ética es filosofía práctica. No es configuración de la vida humana por encima de la cabeza del hombre, sino precisamente su inclusión para la propia configuración libre de la vida. Ella es su saber del bien y del mal, que lo iguala a la divinidad, su fuerza y disposición para participar en el acontecer del mundo, para colaborar en la fábrica de la realidad. Es la educación para su profesión universal, la exigencia dirigida a él para ser co-figurador del demiurgo, co-creador del mundo." (E, Einl., 4.) "La ética con su complejo problemático es el natural abogado del hombre en la metafísica. Ella lo defiende contra todo rebajamiento por obra de la especulación de altos vuelos, contra toda entrega de sus especiales derechos a Dios y al mundo. También lo rehabilita cósmica y metafísicamente. para ella no necesita él de medios especulativos ningunos. Puede atenerse simplemente a sus fenómenos. La ética se halla más cerca de los hechos que la metafísica universal. Su posición es la más fuerte." (E, 21. K., d, 207.) "La elica puede dejar espacio a la metafísica de la fe, en tanto ésta no transgreda sus dominios. Pcro, asl como ésta tuvo que devolver cl ser en sí ideal de los valores, lo cual era propio de aquélla, aś tiene también que devolver al hombre lo que es del hombre". ( $E, 20, \mathrm{~K}$., $\mathrm{f}, 199$.$) "...la ética... se halla dispuesta$ total y absolutamente de este lado. Las materias de todos los valores morales conciernen a la conducta concreta del hombre en este mundo respecto de hombres de este mundo. En 
atributos divinos, reviste en primer lugar un carácter positivo y objetivo, sin sacar ninguna conclusión en disfavor de Dios. Simplemente se afirma y se inculca el inmenso valor que tiene para el hombre el que su esencia no sea otra sino la de Dios mismo: ello, en efecto, pone en sus manos poder y facultades extraordinarias, muy por encima de la naturaleza. Esa posición le permite domeñar los procesos causales y dirigirlos hacia los fines que él mismo se propone. La providencia y la predestinación, antes atributos de Dios, ahora son los suyos. Éstos lo hacen ser persona moral, sujeto capaz de valores y disvalores. Su esencia, su esencia metafísica, lo más profundo y maravilloso que hay en el hombre, es lo propio de Dios. ${ }^{23}$

Esa igualdad del hombre con Dios, sin embargo, no es total y absoluta, como ya se advertía antes. Una identificación semejante traería como consecuencia, entre otras cosas, la no-negación de Dios que Hartmann, en general, tiene en mente. Porque, de admitir un modo de ser absoluto, infinito y perfecto para los caracteres esenciales del hombre, que se identifican con los atributos de Dios, se seguiría la aceptación y posición claras, objetivas, ciertas, de un ser divino, aun cuando esto condujera a un panteísmo. Por ello, sin duda, Hartmann añade a los asertos anteriores las precisiones necesarias. La igualdad de que se trata es radical, fundamental, en el contenido; la forma, el modo de ser, es diverso. Como ser finito, el hombre vuelve finitos, "finitiza" los atributos divinos. Lo que no tiene de Dios es la infinitud. La divinidad del hombre es moderada, disminuida. A fin de poder soportar, poseer Jos atributos divinos en toda su plenitud, necesitaría el hombre una capacidad y una responsabilidad ilimitadas, ajenas a su esencia. ${ }^{24}$

este mundo se halla también el horizonte de los ideales morales más lejanos." (E, 85. K., b. 811.)

23 "Son los atributos de la divinidad, providencia y predestinación, los que dan al hom. bre ésta su posición de poderio. La determinación final, efectivamente, está en posibilidad de desviar la amplia corriente de la determinación causal óntica, y de orientarla a fines establecidos." (E, 21 . K., d, 208.) "La teleologia del hombre es el segundo atributo de la divinidad en él, la predeterminación, la predestinación... El obrar del hombre se distingue internamente respecto del actuar de otras fuerzas, porque él trae a la realidad algo predeterminado." ( $E, 3^{6}$. K., h, 359.) En la providencia y predestinación "se halla la determinación básica del hombre como persona moral. Pues precisamente estos actos, que intervienen por anticipado, son con los cuales el hombre es portador de valores y disvalores morales. Y aquí precisamente se abre una vision metafisica de la esencia del hombre. Pues providencia y predestinación son los atributos de la divinidad, cuya sabiduría, poder y gobierno supremo del mundo deberían manifestarlos." (E, 20. K., f, 199.) "La finitización [en el hombre] no debilita los predicados de la divinidad... El ethos del hombre -y esto es lo peculiar de la personalidad en él_- es en esencia igual a lo que la fe venera en la divinidad... La libertad de decisión, el poder del fallo soberano, es el supremo don de que participa el hombre, la verdadera maravilla de su esencia, lo más metafísico y semejante a Dios en él..." (PgS, 15. K., a, 163-66.)

24 "Estos predicados [de la divinidad] aparecen solamente empequeñecidos, hechos finitos en el espiritu finito; pero radicalmente son los mismos. El hombre es providente en una medida mínima, pero suficiente para ver delante de sí el campo abierto de la actividad. Predestina un devenir futuro dentro de los limites estrechos de sus medios de poder... 
El sentido de la identificación que formula Hartmann entre Dios y el hombre no es el mismo de la idea expresada en el dii estis cristiano o en el eritis sicut dii bíblico, que implica la elevación del hombre hasta la divinidad, la donación generosa del creador a la.creatura de algo por encima de la naturaleza de ésta. Al contrario significa el rebajamiento, el "destronamiento" de Dios o de lo divino hasta hacerlo algo simplemente humano. Es, como se dijo antes, más bien la "devolución" que debe hacerse al hombre de aquello a lo que él mismo había renunciado, es la entrega a él de la herencia que se había asignado a Dios. También debe añadirse que la identificación constituye más bien un desplazamiento y una sustitución, es decir, lo humano real, que "existe", sustituye a lo divino hipotético, que sólo "es". La identidad sería sólo formal e hipotética. Ahora bien, la conclusión última es que, estrictamente, no hay tal identidad, porque para ella se necesitan dos miembros; aquí sin embargo, sólo hay uno: los caracteres del hombre, únicos que "son" y "existen". 25

Sólo como complemento cabe mencionar aquí, por último, las referencias, expresas algunas veces, implícitas las más, de dos atributos especificos de lo humano, estrechamente vinculados entre sí y en ocasiones identificados: la libertad ética, no sólo frente a la naturaleza sino también frente a Dios, y la autonomia radical de los valores morales. ${ }^{26}$

Según, pues, lo expresado por Hartmann con relación al problema Dioshombre, las necesidades manifestadas por éste y procedentes de su esencia o atributos, se reducen fundamentalmente a las mismas cuatro de Dios: libertad, previsión (providencia), predeterminación (predestinación) y conciencia de los valores. En cuanto a la autonomía de éstos puede considerarse como el aspecto objetivo de la libertad, así como ésta sería el aspecto subjetivo de aquéllos.

Sólo le falta además la infinitud. Pues ésta convierte a cada uno de aquellos predicados en absoluto. Para tener estos predicados en una completa ilimitación en sí se necesita una resistencia ilimitada. De ésta el hombre se halla muy lejos. Su 'divinidad' es apenas moderada, se equilibra con sus fuerzas." ( $\left.P g S, 15 . \mathrm{K} ., \mathrm{a}, 1_{3}-64.\right)$ "La idea de Dios como un ser que todo lo predestina es la idea de una responsabilidad ilimitada, pero también naturalmente la idea de una capacidad de responsabilidad ilimitada. La potencia moral se pensó aqứ elevada aun hasta el infinito. El hombre no es un ser semejante. La medida de la responsabilidad que puede soportar es estrechamente limitada... El hombre no puede soportar el segundo atributo de la divinidad aun menos que el primero en toda su extension." (E, $3^{6 .}$ K., h, 359-60.)

25 "La ética hace - y tiene que hacer - lo que a los ojos del hombre piadoso es blasfemia: le da al hombre los atributos de la divinidad. Le da nuevamente lo que él, desconociendo su propio ser, había rechazado de sí y entregado a Dios. $O$, si se quiere expresar esto de otra manera, ella hace a la divinidad descender de su trono sobre el universo y la hace habitar en la voluntad del hombre. Al hombre le corresponde la herencia metafísica de Dios." (E, 20. K., f, 199.)

26 En la Ethik, passim. 


\section{c) Las consecuencias del enfrentamiento entre Dios y el hombre}

De acuerdo con lo expresado ya -y confirmado en algunos textos- así como por el tenor general del pensamiento de Hartmann, el resultado de la confrontación divino-humana parece manifiesto. La balanza se inclinará natural y necesariamente del lado del hombre. Éste tiene en su favor el peso de los hechos, de lo objetivo, de los fenómenos, y la solidez de la realidad consistente y existente. Dios en cambio flota en el aire de lo subjetivo y fantasioso, como hipótesis o postulado especulativo, como concepto, idea o ideal, como anhelo, nostalgia o fe. Esto, según se dijo antes, se refiere al aspecto formal. En ello la posición de Hartmann, de acuerdo con sus puntos de partida, es correcta lógicamente: si el ser y la existencia de Dios se apoyan en las bases gnoseológicas que él sostiene, se sigue su consecuencia. Pero en el aspecto material es donde se da con propiedad el enfrentamiento y el choque: porque los atributos, por su identidad, coinciden en el mismo plano y no pueden ambos subsistir y coexistir; la providencia y predestinación divinas exigen para sí el mismo campo de acción que reivindican como suyo la previsión y predeterminación humanas. La lucha es inevitable; la disyuntiva, ineludible. O el hombre cede, pierde, renuncia, se entrega, se rebaja y degrada delante de Dios -entonces éste prevalece y aquél desaparece, Dios destruye y aniquila al hombre; o al contrario, el hombre se afirma, reivindica sus derechos, reconoce su dignidad, defiende su libertad y autodeterminación, arrebata a Dios lo que le pertenece -entonces Dios no sólo resulta innecesario y superfluo, sino que es inconveniente y perjudicial para el hombre, más aún, no puede ni debe existir, el hombre rechaza y niega a Dios.

El fundamento capital de la argumentación de Hartmann para la negación de Dios o para la destrucción del hombre es el absoluto determinismo finalista implicado por la providencia y predestinación divinas. En diversos contextos, relativos al problema de Dios, compara el sentido y alcance para el obrar humano del determinismo causal, por un lado, y del determinismo finalista, por otro. Partiendo de su división de las capas o estratos del ser, y del principio de determinación o configuración de los inferiores por los superiores, señala que el nexo causal, a pesar del ciego y necesario determinismo óntico que implica, no ofrece sin embargo ningún obstáculo para el nexo finalista - sea de Dios sea del hombre-, el cual se superpone al primero, porque los estratos son diversos. Pero en cambio, la providencia y predestinación divinas, con el absoluto teleologismo que exigen, sí impiden radicalmente el nexo finalista del hombre, porque el estrato es el mismo.

El proceso de la argumentación anterior puede describirse un poco más en detalle con los dos giros siguientes: 1) si, por una parte, se da teleología universal, teleologismo, determinismo finalista total, entonces: no queda ya para el hombre sitio en el mundo; el hombre pierde su libertad, su auto 
determinación, su responsabilidad, etc.; los valores son heterónomos; y en general, el hombre es destruido. Ahora bien, a la inversa: para que el hombre tenga un sentido y un lugar en el mundo; para que sea libre, autodeterminante y responsable, etc.; para que los valores sean autónomos; y para que el hombre en cuanto hombre no sea aniquilado, es necesario que no exista ninguna teleología universal. 2) Si, por otra parte, se da teleología universal, teleologismo, determinismo finalista total, tienen éstos que derivar necesariamente de la providencia y de la predestinación de Dios. O también, a la inversa: si existe Dios, habrá de darse por necesidad providencia y predestinación divinas, y por tanto teleologia universal.

Así pues, el fundamento de esa teleología —si es que está presentesólo puede ser Dios. Es decir, la teleología presupone necesariamente la existencia de Dios; o bien, ella es una consecuencia necesaria, si es que Dios existe. Se podría representar la siguiente cadena desde arriba o desde abajo: Dios - teleologia - destrucción del hombre; o bien: persistencia del hombre - ninguna teleologia - ningún Dios. Es pertinente hacer aqui una distinción un poco sutil, pero que tiene gran importancia en orden a las conclusiones finales y para hacer mayor justicia al filósofo: Hartmann no dice apodícticamente de manera directa e inmediata: Dios significa la des. trucción del hombre; o bien: la persistencia del hombre exige que Dios no exista. Sino esto: admitido que se dé una teleologia universal, supresto que se den predestinación y predeterminación divinas, y todas las otras exigencias y requerimientos de Dios para el hombre -que significarían su destrucción-, entonces y sólo entonces Dios no puede ni debe existir.

Con relación al punto delimitado en este párrafo se encuentran las afirmaciones más inequívocas y rigurosas, casi se diría violentas, en contra de Dios, es decir, en contra de la acción de Dios sobre el hombre - sin duda en el marco de determinadas concepciones tradicionales sobre Dios. Hartmann se sirve de toda una gama terminológica para señalar los diversos aspectos y grados de la obra negativa de Dios sobre el hombre, desde los más radicales, como aniquilamiento y destrucción, siguiendo por los de degradación, eliminación, supresión, rebajamiento, traición, desmoralización, desviación, encadenamiento, impotencia, parálisis, impedimento, amenaza, etc. $\mathrm{Y}$ conviene advertir, una vez más, que esas acciones se le atribuyen a Dios casi siempre indirectamente a través del determinismo teleológico. ${ }^{27}$

27 "La providencia divina, que amenaza al hombre en su autonomía y consecuentemente tiene que aniquilarlo, en donde se la toma de manera absoluta (teoría de la predestinación), fue pensada finalmente como dominando en el mismo mundo, contra cuyo proceso natural la libertad ética tiene que protegerse." $\left(E, 66 . \mathrm{K} ., \mathrm{b}, 6{ }_{32}\right.$.) “... [así se muestra] cuán crudamente antitéticas son esas consecuencias de la providencia divina respecto de la exigencia de libertad de la ética. En ellas la providencia del hombre ha sido absolutamente eliminada, su autodeterminación degradada a apariencia, su ethos aniquilado, su libertad paralizada. Toda iniciativa y toda teleología han sido trasladadas a Dios. (...) Así, el determinismo final de la providencia divina suprime la libertad ética." $(E, 85$. K., 
Otro enfoque que da Hartmann al problema planteado por la providencia y predestinación divinas es el de la imposibilidad para la propia decisión y la personal auto-determinación, cuando se está bajo el peso y yugo del determinismo finalista. La omnipotencia de éste penetra hasta los más íntimos actos, las más secretas mociones del alma y del corazón del hombre. En tal situación, el mundo y la realidad serían únicamente el campo de acción, el espacio abierto, ora para el determinismo causal de la naturaleza -que no ofrece obstáculos al hombre-, ora para el determinismo final de la providencia divina -que sí impide la acción teleológica de éste. El determinismo desplaza al hombre del mundo, no le deja lugar ni campo de acción, a menos que se someta a la determinación causal óntica de la naturaleza -cosa inevitable y admisible - y a la determinación final axiológica de Dios —cosa inaceptable. En suma, encerrado en ese círculo el hombre, resulta imposible toda libertad moral.28

En otro contexto la tesis religiosa de la redención le sirve para insistir

815.) “... si el nexo final domina los procesos de la naturaleza, se enfrentan fines universales dominantes y macrocósmicos a la actividad final finita del hombre, contra los cuales él no puede salir adelante. Se halla impedido, encadenado, predestinado hasta en sus más secretos movimientos del corazón, es más, hasta en su sentimiento de los valores. Esta parálisis del hombre es con toda propiedad su des-moralización." (E, 71. K., g, 674.) "En esta absoluta dominación categorial de la determinación teleológica el sentido estricto de la libertad moral queda completamente aniquilado." (E, 7o. K., f, 679.) "El determinismo final... se ha desenmascarado como el auténtico mal, como el destructor de la libertad humana." ( $E$, 7o. K., a, 664-65.) "Que a él [el hombre] le importe además una cosa cualquiera en el cielo o en la tierra, y así sea Dios mismo, sería éticamente erróneo, inmoral, una traición al hombre -la cual queda dependiendo únicamente de él." (E, 85. K., 812.) "Aquí se deja ver aún detrás de la teología moral también la moral teológica, una tendencia que conduce directamente a la supresión de toda autonomia de lo ético absolutamente, porque concierne a la autonomía misma de los valores morales." ( $E$, 25. K., e, 249.) "Este [el nexo final], convertido en principio universal, quita el derecho al hombre.- La humanización metafísica del universo es la aniquilación moral del hombre. (E, 21. K., e, 206.)

28 “Cómo puede, donde dominan la providencia y la omnipotencia divinas, quedarle al hombre su autodeterminación?... Frente a un ser omnipotente y omnisciente, la cuestión de un espacio libre para la propia decisión del ser finito, se halla de antemano naturalmente en una situación más desfavorable que frente a simples mandatos o valores, que como tales no ejercen ninguna providencia." ( $E$, 66. K., a, 631.) "Como la fuerza determinante en ellos [los fines últimos] es infinita y 'todopoderosa', y además de esto penetra todo acontecimiento mundano - también el pequeño mundo anímico del hombre_, éste es impotente con su teleología frente a aquélla. Ya no encuentra aquí ningún campo de acción para su autodeterminación; más correctamente, lo que le aparece como autodeterminación, es en verdad el poder activo de la providencia divina, que actúa a través y por encima de él." ( $E$, 85. K., 814-15.) "En un mundo determinado completa: mente en sentido final..., la libertad moral es una cosa imposible. La estructura categorial del nexo final la excluye. Si la teleología de los procesos entitativos estuviera fija, no quedaría para el ser de la moralidad absolutamente ningún campio de acción en el mundo, y todos los fenómenos éticos serian fenómenos aparentes. El hombre estaría ya predestinado en su voluntad, en su actividad, es más, en toda su conducta en general... Para un ser moral no habría aqui espacio ninguno. El 'hombre' es posible sólo en un mundo no determinado teleológicamente." $(E, 69 . \mathrm{K} ., \mathrm{e}, 663$. 
duramente, con términos quizá los más excesivos, contra sus consecuencias para la autonomía del hombre, mencionando como una de las razones para rechazarla el orgullo de éste. El perdón de la culpa y la redención se oponen directamente a todo lo ético, a la moralidad, a la libertad; ese perdón sería el único verdadero mal moral en el hombre, porque no sería él el autor de su moralización. ${ }^{29}$ Asimismo, a partir de la imagen también religiosa de la creación del hombre, Hartmann hace una crítica irónica de la misma, señalando cómo las consecuencias son absurdas para Dios mismo, pues la perfección y belleza divinas, como objeto adecuado, y la sabiduría y omnipotencia, como instrumentos capaces, deberían producir una obra perfecta, es decir, un hombre con providencia y predestinación propias y no obstaculizadas. ${ }^{30}$

\section{d) Antinomia e indiferencia de la ética en el problema Dios-hombre}

Las afirmaciones y argumentos de Hartmann presentados en el párrafo anterior parecen no dejar ninguna duda sobre su tesis acerca de las consecuencias nefastas para el hombre, si Dios existe, o más bien, si un semejante o determinado Dios existe: precisamente aquel cuyos atributos, exigencias y acciones adopta Hartmann de la tradición mítico-religioso-teológica. Sin embargo, su posición ofrece con claridad dos atenuantes: el primero es la antinomia que resulta entre los asertos religiosos, por una parte, y los éticos, por otra; el segundo es la neutralidad o indiferencia de la ética en cuanto tal respecto de la afirmación o negación, de la demostración o paralogismo, de la existencia de Dios. Ambos puntos y sus consecuencias tienen como base los diversos planos en que se mueven la religión y la ética. En efecto, la antinomia fundamental en el problema de Dios no se manifiesta internamente en el campo filosófico, porque no hay datos fenoménicos objetivables para la existencia de aquél -y si se presentara la antinomia, se resolvería por lo menos en principio: sólo se presenta ella auténticamente en el entre-

29 "La condonación de la culpa es falsa éticamente, errónea; es algo que al hombre no le es permitido querer y que como ser moral no puede querer..., pues seria realmente un mal moral, la des-liberación y degradación del hombre, su declaración de no-libertad. En sentido moral es ello un no-deber-ser. El que es libre moralmente tiene que oponerle la voluntad de la culpa, el orgullo moralmente justificado de la autodeterminación... La redención misma es éticamente contraria a los valores, prescindiendo de que también es imposible éticamente." (E, 85. K., 819.)

30 "En el fondo es un falso temor de Dios, si para gloria suya sc renuncia al ethos del hombre. En verdad con ello se degrada al creador del mundo a un ignorante que no sabe lo que crea. Con lo supremo - de la propia divinidad-ante los ojos tendría que haber creado una imagen exacta de lo divino, un mundo que tomara precisamente en forma perfecta el esplendor de Dios, esplendor que únicamente habría podido hallarse en la providencia y autodeterminación de una criatura. $\mathrm{Y}$ después de que creó así el mundo, y de que puso ahi al hombre, tuvo que condenarlo por motivo de su 'pecado', como si no hubiera podido más bien radicalmente preservarlo de la capacidad de pecar." $(E, 85$. K., 816.) 
cruce posible de los contenidos de las afirmaciones hechas por la religión y por la ética, donde tienen ellas sin duda un "nexo interno profundo". Para la antinomia se requiere una convergencia y una divergencia, ésta última radical, que es el fundamento de la insolubilidad. En la antinomia coincide el contenido, pero difiere el plano, el punto de arranque y el medio conocitivo. Ahora, en cuanto a la neutralidad de la ética en el problema, ésta presupone la distinción aludida, porque indiferencia o neutralidad no puede haber dentro del plano filosófico mismo, es decir, con relación a cuestiones dilucidables por los mismos o equivalentes métodos, conocibles por las mismas facultades, enfocables desde los mismos puntos de partida -y esto por más que Hartmann establezca diferencias importantes entre la ética, por ejemplo, y la metafísica, ésta más bien entendida tradicionalmente. Si Hartmann concediera al menos un mínimo de posibilidad al tratamiento filosó fico del problema de Dios, no podría haber, por tanto, indiferencia ninguna. Pero en cambio, sí puede haber neutralidad respecto a tesis y conocimientos cuyo origen próximo o remoto se halla en otros planos, métodos, puntos de partida y facultades.

Siguiendo de cerca a Hartmann en los lugares sobre estos dos temas, se advierte que las afirmaciones relativas a la antinomia y su naturaleza son inequivocas y se repiten con frecuencia; en ellas también se destaca a cada paso la diferencia de niveles entre la religión y la filosofía, particularmente la ética. En unos pasajes Hartmann establece simplemente la antinomia y su origen, mientras en otros, discurriendo un poco más a fondo, recalca la insolubilidad de la misma - por eso es tal- "en principio" y "para la razón". Sin embargo, hay un momento en que el filósofo admite cierta posibilidad de solución, diciendo que lo sería en el campo de lo "irracional", sin explicar, empero, ni cómo ni dónde se verificaría ello. ${ }^{31}$

31 "Ahora, si se reflexiona que precisamente esta completa degradación, la destrucción y el rebajamiento del hombre es lo que ha de tener él ante Dios, entonces se ve de inmediato que aquí hay una antinomia radical, en la que una vez más se hallan enfrentadas tesis y antitesis en una forma estrictamente contradictoria." ( $E, 85$. K., 819.) "Pero si se deja valer Ia libertad de la persona, indefectiblemente suprime ésta a aquélla. Ambas están una frente a otra contradictoriamente, como tesis y antitesis." (Ibid., 815.) "Ahora bien, si una vez se introduce con la providencia divina el determinismo finalista total, cntonces se le enfrenta un obstáculo manifiestamente insuperable. La nueva aporia de la libertad religiosa no puede resolverse de ninguna manera. Precisamente la libertad religiosa del hombre ya no es libertad frente a la ley natural y a la ley del deber, sino frente a la voluntad de Dios en el mundo y en él mismo. Esto es lo que hace a esta antinomia insoluble en principio." (Ibid., 815-16.) "La segunda antinomia traslada la disputa a la relación entre el hombre y la divinidad como estrato supremo valioso. No coincide con la primera, sino que se cruza con ella. A la ética, en último término, le importa siempre el hombre; al pensamiento religioso, Dios... También ésta es una antinomia total, auténtica, no resoluble para la razón..." (Ibid., $8_{12}$.) "La tendencia al más allá es desde el punto de vista ético tan antivaliosa, como la tendencia al más acá desde el punto de vista réligioso. Aquélla es desviación y des-orientación de la fuerza moral respecto de los verdaderos valores y de su realización, y por lo mismo inmoral. Para un impulso moral toda trascendencia es una apariencia engañosa. (...) Esta antinomia no puede resolverse 
El pensamiento de la neutralidad o indiferencia de la razón práctica respecto del pro y el contra en el problema de Dios puede considerarse como paralelo y correspondiente de la tesis sobre la incapacidad de la razón teórica para demostrar o para refutar la existencia de Dios. En efecto, así como no existen puntos de arranque dados en el plano gnoseológico, así, según Hartmann, tampoco se pueden establecer inferencias o postulados a partir del plano ético. Sin embargo, el conjunto de las afirmaciones hechas en el primer plano no encierra incongruencia alguna, todo converge y concluye en el agnosticismo: no hay argumento que demuestre ni tampoco que refute la existencia de Dios, éste queda por completo fuera del ámbito y alcance del conocimiento objetivo, real y válido. En cambio, en el segundo plano -ético- sí hay o parece haber, si no contradicción evidente y expresa, por lo menos grave incongruencia entre la conclusión sobre la necesidad de que Dios no exista, a fin de que pueda existir el hombre, y la afirmación sobre la imposibilidad de hacer deducciones desde la ética sea en favor sea en contra de la existencia de Dios.

El fundamento de esta rectificación o limitación de su tesis puede hallarse en la distinción expuesta antes entre la esfera religiosa y la filosófica, pues es manifiesto que en sus disquisiciones contra Dios Hartmann parte fundamentalmente de la tesis de la religión y de sus residuos en la filosofía. Planteado así el problema, no parece objetable que Hartmann concluya, en último término, que la ética -entendida como él la entiende: inmanente y con bases fenoménicas y empíricas- es neutral frente a las afirmaciones religiosas acerca de un ser trascendente y divino, el cual quedaría fuera de sus alcances - por más que no sea neutral la ética frente a las tesis de la religión que afecten directamente al hombre. En suma, puede tal vez concluirse que Hartmann estaría dispuesto a admitir una religión y un Dios que no significaran nada negativo para el hombre.

Al tratar este punto, rechaza la posición de Kant -resultaría extraño, en efecto, que no tomara partido frente a la clásica doctrina kantiana de los postulados; pero además critica la tesis de Scheler, quien no obstante rechazar también a Kant, coincide sin embargo con sus resultados. Contra ambos sostiene claramente: que de la ética no se puede concluir ni deducir nada sobre la existencia de Dios; que no pueden darse desde la ética resultados teológicos concomitantes; que a partir de ella no se puede afirmar ni negar nada sobre Dios; que es al respecto absolutamente indiferente; que se halla, en fin, más acá del teísmo y del ateísmo.32

mediante compromisos ningunos. (...) En el fondo son tendencias estrictamente contradictorias. Cada una niega a la otra; una de las dos tiene que ser necesariamente ilusoria. Si pudiera resolverse la disputa, en todo caso no lo sería en favor de la ratio, sino más allá de ellá, en lo irracional." (Ibid., 811.)

32 "Pero como existe un nexo profundamente interno entre ambos dominios, la perspectiva de la ética lleva más allá de sus propios problemas _en línea recta a los proble- 


\section{Conclusiones y juicio critico}

La honda y un tanto extraña preocupación de Hartmann por el problema de Dios ha quedado bastante clara en los textos de que parte esta exposición. En cierta medida también la extrañeza misma puede considerarse explicada en virtud del propósito que persigue él en la ética y en los puntos conexos de otras disciplinas. Sin embargo, entre los filósofos contemporáneos su actitud no deja de ser peculiar.

El pensamiento "teológico", llamémoslo así, de Hartmann es muy complejo y plantea serias dificultades para llegar a conclusiones claras y definitivas. Un trabajo fundamentalmente expositivo como el actual sólo puede ofrecer apenas los puntos de partida para el planteamiento del problema y las bases para tratar de llegar a una solución. Es indudable que un estudio crítico amplịo, detallado y profundo (en orden al cual éste pudiera ser un ensayo) ofrecerá resultados satisfactorios. Una investigación semejante ha de analizar en todo su ámbito y alcance la sutil teoría hartmanniana de la modalidad y otras principales doctrinas ontológicas, como la de los estratos del ser y sus interrelaciones, la de la estructura del nexo final frente al causal, etc., pero también deberá adentrarse en problemas gnoseológicos fundamentales, en los que se basa su agnosticismo. Sobra añadir, sin duda, que los conceptos éticos capitales como libertad, autodeterminación, autonomía de los valores, conciencia de los mismos, etc., deben también profundizarse, especialmente en los aspectos donde se entrecruzan con los atributos divinos. A pesar de lo anterior es posible, y aun obligado, sacar algunas conclusiones claras, aunque generales, que orienten al menos con seguridad hacia la solución definitiva.

En el plano teórico es manifiesto que Hartmann sostiene sin vacilaciones ni restricciones el agnosticismo: sus argumentos contra la demostración de la existencia de Dios en general, así como en particular contra cada una de las pruebas, coinciden acordes en negarle capacidad a la razón humana para

mas religiosos. Pero no como si se siguiera de ellos algo sobre la existencia de Dios o cosa semejante; no como si se pudiese enlazar con las cuestiones éticas tan siquiera una doctrina de los postulados en el sentido de Kant..." (Ibid., 809.) "Ciertamente no se tiene ningún fundamento para esperar de los problemas éticos que ofrezcan algunos resultados teológicos adicionales. Aun el procedimiento de Kant, de basar moralmente los conceptos teológicos fundamentales, atrajo hacia sí precisamente la indignación del auténtico pensamiento teológico. El personalismo de Scheler, a pesar de todo su rechazo de Kant en general y de la doctrina de los postulados en particular, comete una transgresión de límites del todo análoga. El concepto de persona, empero, no soporta esa transgresión. Si en otro caso tiene tal concepto aún una significación y si le corresponde él a la divinidad, desde la ética no se puede ni afirmar ni negar." (E, 25. K., e, 248-49.) "...sólo el pensamiento religioso la implica [la providencia divina], respecto del cual toda la cadena problemática de la ética se halla absolutamente indiferente -está más acá del teismo y del ateismo. Y sólo con ello se presenta la antinomia." $(E, 85$. K., 815.) 
conocer o desconocer, demostrar o refutar, en forma objetiva, real y válida, cosa alguna acerca de Dios; todo lo que a Él se refiere queda fuera del ámbito, del horizonte y del alcance del conocimiento humano. Como puede con facilidad advertirse, esta posición, a despecho de algunas diferencias accidentales, si bien importantes, es esencialmente la tesis de Kant - con lo cual no se quiere afirmar precisamente una dependencia de las doctrinas de Hartmann respecto de las de aquél, o pasar por alto las diferencias básicas, como la del realismo hartmanniano. Aspecto de gran valor para el juicio crítico es, por ejemplo, la distinción que hace Hartmann entre la demostración de una cosa - y su validez o ineficacia - y la existencia de la cosa misma. De todo esto resulta claramente que en el plano teórico Hartmann no niega la existencia de Dios, sino que sólo critica las pruebas y les niega toda validez. Es cierto, sin embargo, que la refutación de los argumentos, atribuyendo sus bases últimas a la injustificada pretensión humana de satisfacer necesidades e inquietudes, hace sentir que Hartmann no cree en la existencia de Dios, porque no la considera necesaria para los fines pretendidos por el hombre.

En cuanto a la refutación concreta de cada una de las pruebas, debe decirse que sólo en la relativa a la contingencia hay un tratamiento sólijdo y sistemático; en las demás apenas se exponen sumariamente las bases. Pero en casi todas el rechazo suele fundarse no directamente en la discusión objetiva y filosófica de las premisas, sino en el descubrimiento de los trasfondos mítica-religiosos, de ignorancia, necesidad, sentimiento, deseo, etc. Esto, naturalmente, debilita la refutación y hace pensar que Hartmann se acerca al problema teórico con una posición preconcebida desde otros campos. Para el argumento "ontológico" se adhiere expresamente a la refutación tradicional, apoyándola desde sus propias doctrinas.

La crítica al argumento por la contingencia del mundo requeriria una amplia discusión, que no es posible aquí. Me limitaré a dos consideraciones básicas. En primer término, los conceptos de necesariedad y contingencia, según Hartmann y según la demostración tradicional, tienen de común sólo el nombre, pues el contenido es claramente diverso. Por ello Hartmann puede concluir en una de sus formulaciones que el ser absolutamente necesario es más bien el ser absolutamente contingente. Si no se admite esa diversidad, entonces es ineludible la presencia de un sofisma evidente, o en la tradición o en Hartmann. Ahora bien, si fuera posible en la tradición la equivalencia de términos pretendida por Hartmann, resultaría que el argumento ha sido sólo verbal y que en el fondo hubo simplemente una equivocación al tomar una cosa por otra. Pero esto es indemostrable histórica y doctrinalmente. Necesario en la tradición es lo que existe por sí mismo y tiene en sí la razón de existir, no pudiendo no existir; contingente es lo que no existe por sí mismo y no tiene en sí la razón de existir, pudiendo no existir. Hartmann por su parte entiende así esos conceptos: "La necesariedad lleva consigo el prin- 
cipio de su autosupresión e implica con ello a la contingencia como su limitación; la contingencia, por el contrario, no conoce ninguna autosupresión ni limitación, no implica de por si ninguna necesariedad." 33 Aquí se ve con claridad que los conceptos y su sentido no pueden ser los mismos. En consecuencia, debe considerarse invalidada por principio una refutación que emplea otros conceptos y parte de otros presupuestos.

Y la formulación tradicional causa sui, que Hartmann considera en su réplica, es sólo una analogía, que en todo caso de ningún modo significa una relacionalidad externa, la cual sí implicaría en el fondo una dependencia del ser necesario respecto de otro. Por tanto, uno se ve precisado a admitir que Hartmann no advirtió o no consideró existente esa distinción de conceptos, y que, llevado por la claridad de sus propias concepciones, se puso a refutar un argumento que más bien él mismo se había fabricado con sus propios conceptos.

En segundo lugar, respecto a la inferencia o deducción misma de lo necesario a partir de lo contingente, debe precisarse ante todo que en las diversas presentaciones que hace Hartmann de la demostración por la contingencia, se cambia, según los términos empleados, el punto de partida, pues argumenta desde lo necesario: ".... un fundamento sobre el que se apoya la necesariedad de algo...; ... .es al mismo tiempo fundamento de toda necesariedad en el mundo...; si todo lo necesario..." Ahora bien, ese cambio parece ser del todo consciente en Hartmann, pero inexplicable, pues él mismo dice que la demostración tradicional "concluye a contingentia mundi - porque de otra manera, el mundo junto con toda su necesariedad (l) seria, a pesar de todo, contingente en el fondo'." ${ }^{4} \mathrm{La}$ única explicación de esto es que, como se advierte en el desarrollo inmediato al texto citado arriba (cfr. nota 9), Hartmann entiende las cosas primero en el plano formal lógicognoseológico, y después hace derivaciones para el campo material ontológico. Parece manifiesta, por tanto, la metábasis a otro orden. Por otra parte, la demostración tradicional no se funda, como dice Hartmann, sólo "en la indispensabilidad del principio para la consecuencia", ni "confunde" ésta "con la necesariedad del principio mismo", 35 sino que arguye de lo contingente real y dado fáctica y ónticamente, que existe pudiendo no existir, hacia lo necesario, real también ónticamente, que existe no pudiendo no existir. En este respecto Hartmann no parece sacar la conclusión correcta de la distin. ción que hace ahí mismo entre el "fundamento conocitivo de la reflexión" y el "fundamento entitativo de la cosa" (distinción paralela a la establecida entre la argumentación en favor de una cosa y la existencia misma de ésta), según la cual, es cierto, el ser contingente puede considerarse como causa

33 Cfr. nota 8, primer texto.

34 Cfr. nota 8, segundo texto, y nota 9, al principio.

35 Cfr. nota 9 , al fin. 
o razón gnoseológica de la existencia del ser necesario, pero no como causa o razón ontológica del mismo. Porque, para la necesariedad ontológica es indispensable la contingencia gnoseológicamente, pero no así ontológicamente; y a la inversa, para la contingencia ontológica no es indispensable la necesariedad gnoseológicamente, pero si ontológicamente. La razón de esto es que la necesariedad ontológica no es intuida directa y evidentemente, pues si ella fuera intuida o vista desde si misma y sin relación con ningún otro ser, sería sólo lo existente por sí y sin ninguna razón en sí de no existencia -lo que coincide formalmente con lo llamado real por Hartmann. De donde resulta que se trata de una necesariedad interna y no externa. Además, él parece quedarse en el plano puramente lógico-gnoseológico, lo cual, entre otras cosas, se contradice con su realismo ontológico: porque, si el ser no se entrega como contenido del conocer, si no hay una identidad radical y objetiva - no formal- entre conocimiento (intuición, discurso, inferencia, implicación, etc.) y ser (esencia, existencia, facticidad, contingencia, necesariedad, etc.), entonces no queda lugar sino para el silencio o el escepticismo más absolutos. De ahí que la distinción - e independencia - establecida por Hartmann entre demostración -válida o inválida- de una cosa y su existencia, sólo puede admitirse cuando precisamente, y sólo entonces, la no-coincidencia, la no-identidad entre una y otra sean intuidas o apodícticamente demostradas a partir de principios inmediatamente evidentes: porque desgraciada, pero necesariamente, no tenemos otra vía de acceso al ser que a través del conocer.

En el plano ético-práctico la conclusión que señalaría un ateísmo hipotético o postulatorio parece justificada en lo fundamental. Sin embargo, deben hacerse necesariamente varias precisiones. Una de ellas es la señalada al final de la exposición de ese mismo enfoque, acerca de la indiferencia de la ética respecto de toda afirmación negativa o positiva sobre la existencia de Dios, acerca de que el complejo problemático de la ética se halla más acá del teísmo y del ateísmo. ¿Cómo armonizar estas afirmaciones con la tesis capital en ese plano, mostrada en el párrafo sobre las consecuencias para el hombre derivadas de las exigencias de Dios? Si la ética es neutral e indiferente en el problema, si queda fuera del ámbito de las afirmaciones teístas o ateístas, ccómo es que precisamente desde el campo de la ética Hartmann postula su ateísmo? A mi juicio, la aparente contradicción se resolvería así: la ética, como la metafísica del conocimiento, se funda sobre bases conocitivas inmanentes, fenoménicas, realmente válidas, aunque una y otra de diverso modo; ahora bien, toda afirmación sobre Dios es establecida según Hartmann en un plano radicalmente distinto: el del mito, de la religión, de la pseudofilosofía. Por tanto, ni la ética ni la gnoseología pueden decir nada acerca del contenido de tales afirmaciones, porque queda más allá del alcance de sus propios medios: su existencia o inexistencia, metodológica y "cien- 
tíficamente", les es ajena, inaccesible, indiferente. En cambio, acerca de lo formal de esas afirmaciones sí puede decir que es inadecuado e insuficiente para alcanzar lo que pretenden; pero esto siempre desde sus propias premisas filo. sóficas y, sobre todo, en el supuesto de que postan un instrumento adecuado para verificar el no-alcance de los medios conocitivos de la fe o de la pseudofilosofía. En suma, la neutralidad o indiferencia se funda en la diversidad de planos.

Sin embargo, ¿cómo explicar entonces las afirmaciones de carácter ateísta? La razón es que se trataría de una transgresión de dominios, de una intromisión de campos, de una aplicación ilícita de lo sabido y afirmado en un plano, a otro. Hartmann niega a Dios, es decir, rechaza sus atributos, atribuciones, influjos y exigencias, porque y cuando éstos interfieren o se contradicen con los caracteres esenciales del hombre. En otras palabras, si la religión y la pseudofilosofía pretenden inmiscuirse, al menos indirectamente, en la ética; o bien, si sus afirmaciones tienen consecuencias directas $o$ indirectas sobre la ética, deben ser rechazadas y junto con ellas su supuesto autor, Dios. Por el contrario, si la religión y cualesquiera otros pretendidos conocimientos sobre Dios dejan en paz a la ética, si no hacen afirmaciones que directa o indirectamente determinen o pretendan determinar algo en la ética, no hay transgresión de dominios, y la ética se sitúa indiferentemente frente a aquéllas: el que Dios exista o no, sería en ese caso problema que no le incumbe. Pero entonces la dificultad seria ésta: thay o no realmente tal intromisión, transgresión, determinación y aun violencia por parte de la religión en la ética? Hartmann sí las encuentra. ¿Dónde? De acuerdo con la exposición que hace de las doctrinas contrarias, se hallan fundamentalmente en las enseñanzas populares y en algunas doctrinas teológicas del cristianismo, pero sobre todo - aspecto de gran importancia - pueden advertirse en las direcciones rigurosas y extremistas del protestantismo y calvinismo. Hart. mann no parece ocuparse ni preocuparse nunca de las profundas y sutilísimas teorías que trataron de resolver el misterio - la antinomia- entre la gracia y la libertad, y que fueron elaboradas sobre todo en el seno del catolicismo, a partir de las cuales fundamentalmente -aun consideradas sólo como intentos- no pueden ni histórica ni doctrinalmente sacarse las premisas en que Hartmann se funda. En este punto el filósofo merece un grave reproche, una severa crítica, porque si, como lo es en realidad, el problema le preocupa - si bien más por la parte del hombre que por el lado de Dios-, debió adentrarse en esas disquisiciones valiosísimas, aun para la ética, de tantos teólogos, a quienes también, y quizá más que a él, inquietaba ese misterio.

Otra precisión o atenuante - señalada también como la anterior al final de la exposición- es el desplazamiento del estrato para una posible solución desde lo racional a lo irracional, y la calificación del problema como 
una verdadera antinomia y como el punto de contacto de diversos planos con afirmaciones contradictorias. Esto es digno de atención por varios motivos. En primer lugar, con ello la tesis ateísta sigue debilitándose, porque un verdadero ateísmo, aun postulatorio, especulativo o práctico, debe poder afirmarse más acá de lo irracional, en el campo mismo de la razón práctica o teórica. En segundo lugar, el carácter antinómico de dos afirmaciones contradictorias elimina por principio la posibilidad de validez de una o de otra. En fin, lo más importante, este aspecto coincide con el carácter de misterio atribuido en general por la teología al conflicto entre la gracia divina y la libertad y operación humanas, o más bien, al último reducto de la dificultad que significa el impulso conjunto, sobre una y la misma acción, de dos fuerzas, la humana y la divina: necesaria aquélla por tratarse de un acto del hombre, y exigida ésta tanto por el carácter finito y necesitado de la criatura como por el infinito y superabundante del creador. De manera que este pensamiento de Hartmann coincidiría con una doctrina teológica del cristianismo católico, en el cual la radical insolubilidad del misterio para el conocimiento no implica ni conduce al ateísmo.

En cuanto a los conceptos claves de donde parte toda la argumentación - la providencia y la predestinación-, Hartmann los entiende de la manera más absoluta y hermética, llevado sin duda por su tesis extrema del teleologismo. Pero en ninguna parte hay una verdadera demostración de la absoluta incompatibilidad, de la total imposibilidad para coexistir la providencia y predestinación divinas con la libertad y autodeterminación humanas. Hartmann no se plantea jamás la cuestión de una identidad básica entre los fines de Dios y los fines del hombre; para él, los propósitos de uno y otro son diversos, opuestos, contradictorios. ¿Por qué? No lo dice. Como si ambos, Dios y el hombre, no pudieran tener los mismos o parecidos fines; como si, siendo seres análogos, no pudieran coincidir en la tendencia a realizar la perfección y el bien, los valores - uno ad extra, Dios; otro ad intra, el hombre, como dicen los teólogos. Tampoco piensa él en la incorporación o incardinación, pero ni al menos en la coincidencia o paralelismo, entre la teleología humana y la divina, como sucede por ejemplo, en lo humano, dentro de la familia, del Estado o de otras unidades sociales. Además, Hartmann mismo, al comparar la providencia y predestinación de Dios con las del hombre, no sólo admite, sino que afirma que en este último son finitas, limitadas, disminuidas. Si en ambos seres esos atributos se sostuvieran como absolutos, infinitos y perfectos, la contradicción sería evidente -en lo formal, se diría; en lo material, por el contrario, diversas providencias y predestinaciones no se contradicen, a menos que las metas por alcanzar se opusieran diametralmente. ¿Se oponen así los objetivos de Dios y los del hombre? ¿Puede esto demostrarse? ¿Se ocupa Hartmann de ello? A todas estas preguntas la respuesta es no. Las disqui- 
siciones de nuestro autor, sobre todo en este aspecto, suenan más a discursos declamatorios que a razonamientos filosóficos.

Según todo lo expuesto, mostrado y discurrido a lo largo de este ensayo, la posición de Hartmann acerca del problema estudiado aquf, puede resumirse en estos puntos: $I^{o}$ la razón especulativa no puede demostrar ni refutar la existencia de Dios, pues los argumentos para ello son totalmente infundados, quedando tal existencia, vista en sí misma y absolutamente, del todo intocada; $2^{o}$ de la razón práctica, estrictamente, tampoco puede deducirse nada en favor o en contra de tal existencia, porque su radio de acción está más acá de ella; $3^{\circ}$ la oposición y aun contradicción entre el hombre y Dios deriva a una antinomia, que sólo podría resolverse en el plano de lo irracional; $4^{\circ}$ las concepciones sobre Dios de que parte el filósofo son adoptadas en el fondo hipotéticamente, y sin examen crítico sobre su corrección y validez; $5^{\circ}$ mostradas, como es posible, la falsedad e incorrección del punto de partida, desaparecería todo rasgo ateísta y el pensamiento del filósofo podría ser descargado del ateísmo; $6^{\circ}$ y último, la actitud de Hartmann, en todo caso, no es ni anti-teísta, ni directamente atea, sino más bien humanista, elevadora, protectora y defensora del hombre frente a una supuesta acción negativa de Dios contra él.

Bernabé Navarro

INSTITUTO de INVESTIGACIONES FiLosóficas

Universidad Nacional Autónoma de México 